\title{
Loss of Ikbkap Causes Slow, Progressive Retinal Degeneration in a Mouse Model of Familial Dysautonomia
}

\author{
Yumi Ueki, ${ }^{1}$ Grisela Ramirez, ${ }^{2}{ }^{\circledR}$ Ernesto Salcedo, ${ }^{2}{ }^{\circledR}$ Maureen E. Stabio, ${ }^{2}$ and ${ }^{\circledR}$ Frances Lefcort $^{1}$
}

DOI:http://dx.doi.org/10.1523/ENEURO.0143-16.2016

${ }^{1}$ Department of Cell Biology and Neuroscience, Montana State University, Bozeman, MT 59717, and ${ }^{2}$ Department of Cell and Developmental Biology, University of Colorado School of Medicine, Aurora, CO 80045

\begin{abstract}
Familial dysautonomia (FD) is an autosomal recessive congenital neuropathy that is caused by a mutation in the gene for inhibitor of kappa $\mathrm{B}$ kinase complex-associated protein (IKBKAP). Although FD patients suffer from multiple neuropathies, a major debilitation that affects their quality of life is progressive blindness. To determine the requirement for Ikbkap in the developing and adult retina, we generated Ikbkap conditional knockout (CKO) mice using a TUBA1a promoter-Cre $(T \alpha 1-C r e)$. In the retina, $T \alpha 1$-Cre expression is detected predominantly in retinal ganglion cells (RGCs). At 6 months, significant loss of RGCs had occurred in the CKO retinas, with the greatest loss in the temporal retina, which is the same spatial phenotype observed in FD, Leber hereditary optic neuropathy, and dominant optic atrophy. Interestingly, the melanopsin-positive RGCs were resistant to degeneration. By 9 months, signs of photoreceptor degeneration were observed, which later progressed to panretinal degeneration, including RGC and photoreceptor loss, optic nerve thinning, Müller glial activation, and disruption of layers. Taking these results together, we conclude that although Ikbkap is not required for normal development of RGCs, its loss causes a slow, progressive RGC degeneration most severely in the temporal retina, which is later followed by indirect photoreceptor loss and complete retinal disorganization. This mouse model of FD is not only useful for identifying the mechanisms mediating retinal degeneration, but also provides a model system in which to attempt to test therapeutics that may mitigate the loss of vision in FD patients.
\end{abstract}

Key words: familial dysautonomia; IKAP/Elp1; Ikbkap; retinal degeneration; retinal ganglion cell

\section{Significance Statement}

Familial dysautonomia (FD) is classified as a hereditary sensory and autonomic neuropathy (Type III). A classic hallmark of the disease is progressive blindness marked by retinal ganglion cell (RGC) loss and optic nerve atrophy. To investigate the consequences of Ikbkap loss in the retina, we generated Ikbkap conditional knockout mice using TUBA1a-Cre. In the retina, TUBA1a-Cre is expressed primarily in RGCs, and Ikbkap disruption led to slow, progressive RGC degeneration that was subtype and region specific. This was later followed by indirect photoreceptor loss and complete retinal disorganization. Our data demonstrate that this is a powerful model system that faithfully recapitulates the phenotype and progression of FD blindness and can be used to investigate potential therapeutics to treat retinal degeneration in FD.

\section{Introduction}

Familial dysautonomia (FD; also called Riley-Day syndrome) is a fatal autosomal recessive neurodegenerative

Received June 2, 2016; accepted September 14, 2016; First published September 19, 2016. disorder that is caused by an intronic mutation in IKBKAPI Elp1, the gene for inhibitor of kappa B kinase complexassociated protein (IKAP) (Riley et al., 1949; Anderson

The authors declare no competing financial interests.

Author contributions: Y.U., M.E.S., and F.L. designed research; Y.U., G.R., 
et al., 2001; Slaugenhaupt et al., 2001). The T-to-C base change in a splice acceptor site results in variable tissuespecific exon skipping and generates an unstable mRNA that undergoes nonsense-mediated decay, leading to a reduction in IKAP/Elp1 protein, particularly in the nervous system (Cuajungco et al., 2003). The function of IKAP/ Elp1 is unresolved, although the preponderance of evidence indicates that it functions as a key subunit of the six-subunit Elongator complex, which is essential for transfer RNA (tRNA) modification (Huang et al., 2005; Esberg et al., 2006; Bauer and Hermand, 2012; Xu et al., 2015). Symptoms of FD include decreased pain and temperature sensation, orthostatic hypotension, tachycardia, labile blood pressure, spinal deformities, and gait ataxia, and the majority of FD patients die by age 40 (Riley et al., 1949; Axelrod, 2002; Palma et al., 2014; Dietrich and Dragatsis, 2016; Norcliffe-Kaufmann et al., 2016).

Although FD patients suffer from multiple severe neuropathies, a major quality-of-life issue as they age is progressive blindness. Until recently, the visual loss was thought to be due to sensory and sympathetic-related corneal keratopathy and neovascularization, poor ulceration healing, and lack of tears (Goldberg et al., 1968; Liebman, 1968). However, recent studies report retinal dysfunctions in FD patients, including decreased visual acuity, poor color vision and central visual field loss, temporal optic nerve pallor, and delay in visual evoked potentials (Mendoza-Santiesteban et al., 2012, 2014). Reduction in retinal nerve fiber thickness, which is due to loss of retinal ganglion cells (RGCs), was observed in retinas of FD patients (Mendoza-Santiesteban et al., 2012, 2014). This loss in retinal nerve fiber was more widespread in older patients, suggesting the progressive nature of RGC degeneration.

Various mouse models of FD have been developed to understand the disease mechanisms (Chevrollier et al., 2008; Dietrich et al., 2011, 2012; Hunnicutt et al., 2012; George et al., 2013; Morini et al., 2016). The Ikbkap ${ }^{-/-}$ genotype is embryonic lethal owing to a failure in neurulation and vasculogenesis (Chen et al., 2009), and mice that were generated with the human point mutation showed no phenotype (Hims et al., 2007; Bochner et al., 2013). In contrast, Ikbkap conditional knockout (CKO) and

and M.E.S. performed research; Y.U., G.R., E.S., and M.E.S. analyzed data; Y.U., M.E.S., and F.L. wrote the paper; F.L. contributed unpublished reagents/ analytic tools.

This work was supported by NIH F32 EY023498-01A1 (to YU) and NIH R01 NS086796 and the Dysautonomia Foundation (to FL and MES).

Acknowledgments: We thank Tom Finger, Nicole Shultz, Jennifer Stratford, and Shilo Smith in the Department of Cell and Developmental Biology at University of Colorado School of Medicine for technical support, and Lino Tessarollo (NCl) and George Carlson (McLaughlin Research Institute, Great Falls, MT) for help with mouse genetics and kind gift of mouse line. We also thank Carlos Mendoza-Santiesteban and Nora Laver (Tufts Medical Center, Boston, MA) for helpful discussion.

Correspondence should be addressed to Yumi Ueki, 109 Lewis Hall, Bozeman, MT 59717. E-mail yueki@montana.edu.

DOI:http://dx.doi.org/10.1523/ENEURO.0143-16.2016

Copyright (C) 2016 Ueki et al.

This is an open-access article distributed under the terms of the Creative Commons Attribution 4.0 International, which permits unrestricted use, distribution and reproduction in any medium provided that the original work is properly attributed. hypomorphic mice have provided useful information on the role of IKAP in peripheral nervous system (PNS) development and maintenance (Dietrich et al., 2012; Hunnicutt et al., 2012; George et al., 2013; Jackson et al., 2014; Morini et al., 2016). Our previous study in a PNS model of FD demonstrated that subsets of PNS neurons die by p53- and activated caspase-3-mediated apoptosis in the absence of lkbkap (George et al., 2013).

Although there is great interest in developing treatments to prevent or delay the progressive retinal degeneration to improve FD patients' quality of life, no study has been published to date that investigates the progression and causes of FD blindness. To this end, we generated a model system in which the consequences of lkbkap loss in the retina could be investigated. We generated lkbkap CKO mice using TUBA1a promoter-driven Cre (T $\alpha 1-\mathrm{Cre})$, which targets postmitotic neurons (Gloster et al., 1994; Coppola et al., 2004; Coksaygan et al., 2006). Our CKO mice display typical FD patient symptoms, including small stature, kyphosis, and gait disturbances (Chaverra M, George L, Mergy M, Waller H, Kujawa K, Murnion C, Sharples E, Thorne J, Podgajny N, Personius K, Grindeland A, Ueki Y, Eiger S, Cusick C, Babcock M, Carlson G and Lefcort $F$, unpublished observations). Here, we show that in the retina, the loss of Ikbkap in RGCs leads to their slow, progressive degeneration, with the greatest demise in the temporal retina-the same pattern observed in FD patients (Mendoza-Santiesteban et al., 2014). Interestingly, melanopsin-positive intrinsically photosensitive RGCs are resistant to degeneration even with widespread loss of conventional RGCs. In older CKO retinas, optic nerve inflammation, photoreceptor degeneration, Müller glial activation, and disruption of retinal layers are also observed. This is the first study to explore the consequences of lkbkap loss in the retina, and the study reveals that this model will be invaluable for investigating the molecular and cellular mechanisms mediating the demise of retinal neurons, and ultimately for designing therapeutic targets.

\section{Materials and Methods}

\section{Animals}

All mice were housed at the Montana State University, and protocols were approved by the Montana State University Institutional Animal Care and Use Committee. Both male and female mice were used for this study. Ikbkap CKO mice were generated by crossing T 1 1-Cre, which targets postmitotic neurons (Gloster et al., 1994; Coppola et al., 2004; Coksaygan et al., 2006) and Ikbkap-floxed mice (International Knockout Mouse Consortium; Chaverra et al., unpublished observations). Mice were used at ages detailed below, and littermate $\mathrm{Cre}^{-;} / \mathrm{kbkap}^{f / f}$ mice were used as controls. To determine Cre expression in the retina, T 1 -Cre mice were crossed to $\mathrm{mTmG}$ reporter mice (stock \#007576; Jackson Laboratory, Bar Harbor, ME; Muzumdar et al., 2007). To analyze endogenous expression of Ikbkap in the retina, LacZ reporter mice (Ikbkap: $\beta$-gal) were used (International Knockout Mouse Consortium; George et al., 2013). 


\section{LacZ staining}

Eyes were enucleated and fixed (1\% formaldehyde, $0.2 \%$ glutaraldehyde, and $0.02 \% \mathrm{NP}-40$ in PBS) for 30 $\mathrm{min}$ at room temperature. The cornea and lens were removed during the first $5 \mathrm{~min}$. Standard LacZ staining was performed at $37^{\circ} \mathrm{C}$ overnight. Eyes were then cryoprotected at $30 \%$ sucrose/PBS and embedded in optimal cutting temperature compound for cryostat sectioning. Sections were analyzed with a light microscope.

\section{Hematoxylin and eosin staining}

Mice were euthanized with $\mathrm{CO}_{2}$, and eyes were marked with a green tattoo dye on the temporal surface. Eyes were then enucleated and fixed overnight in PerFix (20\% isopropanol, $2 \%$ trichloroacetic acid, $4 \%$ paraformaldehyde, and $2 \%$ zinc chloride), placed in $70 \%$ ethanol at room temperature for at least $24 \mathrm{~h}$, and embedded in paraffin for sectioning. Sections $(5 \mu \mathrm{m})$ were cut through the center of the eye (determined by the presence of the optic disc) and stained with hematoxylin and eosin (H\&E). Standard light microscopy was performed to analyze retinal morphology. The number of photoreceptors lying in a single column spanning the outer nuclear layer (ONL) was counted as described previously (Ueki et al., 2008). Counts were made at intervals of $0.25 \mathrm{~mm}$ beginning at the optic nerve head $(\mathrm{ONH})$ and toward both the temporal and nasal retinal hemispheres. Statistical analysis was performed using $t$-test. Data are considered significant when $p<0.05$.

\section{Immunohistochemistry}

Mice and eyes were prepared as above, and eyes were enucleated and fixed in $4 \%$ paraformaldehyde for $30 \mathrm{~min}$ at room temperature (cornea/lens removed). After a single PBS wash, eyecups were cryoprotected in $30 \%$ sucrose overnight at $4^{\circ} \mathrm{C}$ and embedded in optimal cutting temperature compound (Sakura Finetek, Torrance, CA) and sectioned at 12-14 $\mu \mathrm{m}$. For immunohistochemistry $(\mathrm{IHC})$, sections were blocked with animal-free blocker (Vector Laboratories, Burlingame, CA) containing $0.5 \%$ Triton $\mathrm{X}-100$ for $1 \mathrm{~h}$ at room temperature, then primary antibodies were applied and incubated at $4^{\circ} \mathrm{C}$ overnight. Primary antibodies used were anti- $\beta$-galactosidase (Invitrogen, San Diego, CA), anti-GFP (Invitrogen or Abcam, Cambridge, MA), anti-Otx2 (R\&D Systems, Minneapolis, MN), anti-AP2 $\alpha$ (Developmental Studies Hybridoma Bank, lowa City, IA), anti-Brn3 (Santa Cruz Biotechnology, Santa Cruz, CA), anti-RNA-binding protein multiple splicing (RBPMS; PhosphoSolutions, Aurora, CO), antiGFAP (NeuroMab, Davis, CA), anti-Islet1 (Developmental Studies Hybridoma Bank), anti-Sox9 (EMD Millipore, Billerica, MA), anti-Sox2 (Santa Cruz Biotechnology), anti-choline acetyltransferase (EMD Millipore), and anti-PKD2L-1 (EMD Millipore) antibodies. Sections were washed three times with PBS and incubated with secondary antibodies (Invitrogen; Jackson ImmunoResearch, West Grove, PA) and DAPI (Sigma, St. Louis, MO) for $1 \mathrm{~h}$ at room temperature. Sections were coverslipped, and confocal microscopy was performed.

\section{Retinal flat-mount IHC and $\mathrm{Brn}^{+}{ }^{+} \mathrm{RGC}$ counting}

After fixation (as described above), retinas were isolated, and temporal retinas were marked with a small cut.
Nonspecific binding was blocked by incubating with animal-free blocker (Vector Laboratories) containing $0.5 \%$ Triton X-100 overnight at $4^{\circ} \mathrm{C}$, and anti-Brn3 antibody (Santa Cruz Biotechnology) was applied for 2 days at $4^{\circ} \mathrm{C}$. Retinas were washed three times with PBS, incubated with secondary antibodies (Invitrogen) and DAPI (Sigma) overnight at $4^{\circ} \mathrm{C}$, washed three times with PBS, and mounted on slides.

\section{Confocal imaging}

Confocal microscopy was performed using a Leica TCS SP8. To ensure quantitative image quality, laser power, pinhole settings, photomultiplier tube settings, and intensity thresholds were kept constant for a given antibody. For quantifying $T \alpha 1$-Cre expression in RGCs, the number of $\mathrm{RBPMS}^{+}, \mathrm{GFP}^{+}$, and $\mathrm{RBPMS}^{+} \mathrm{GFP}^{+}$cells were quantified at $<0.25 \mathrm{~mm}$ (central) and $1 \mathrm{~mm}$ from the $\mathrm{ONH}$ at temporal and nasal hemispheres. For Brn ${ }^{+}$RGC counts on flat mounts, confocal images were taken at $1 \mathrm{~mm}$ from the $\mathrm{ONH}$ in temporal, nasal, superior, and inferior retinas, and the number of $\mathrm{Brn}^{+}$cells in each image was counted manually. The number of cells in $1 \mathrm{~mm}^{2}$ of the retina was calculated and plotted as a percentage of 1-month-old control retinas. Statistical analysis was performed using $t$-test. Data are considered significant when $p<0.05$.

\section{Optic nerve analysis}

The optic nerve was carefully cut away from the eyecup after $4 \%$ paraformaldehyde fix described above, rinsed in PBS ( $3 \times 15 \mathrm{~min})$, and stored in PBS for later use. Nerves were cryoprotected overnight with $20 \%$ sucrose in phosphate buffer (PB) and sectioned by cryostat (longitudinally) at $16 \mu \mathrm{m}$ onto Tanner positively charged slides (Light Labs, Aurora, CO). Slides were then incubated overnight in anti-lba1 antibody (Wako Chemicals USA, Richmond, VA). The next day, slides were rinsed in $0.1 \mathrm{M}$ PBS and incubated for $2 \mathrm{~h}$ with a secondary antibody. The slides were washed two times for 10 min each in PBS and then once for 10 min in PB before being coverslipped with Fluoromount G (Southern Biotech). Optic nerve sections were imaged with $0.5-\mu \mathrm{m} z$-step sizes using a Leica TCS SP5 Confocal Laser Scanning Microscope. The confocal image stacks were then analyzed using our in-house imstack toolbox developed using the MATLAB programming language (Mathworks, Natick, MA). Briefly, we loaded each $z$-stack into the imstack toolbox. We then drew a rectangular region of interest $(\mathrm{ROI})$ with a maximum area contained entirely within the optic nerve and extended the $\mathrm{ROI}$ throughout the $z$-stack, ensuring that the 3D ROI did not capture any area outside of the optic nerve. This 3D $\mathrm{ROI}$ established our analysis volume. We next calculated a threshold value using the method of Otsu (1979) and adjusted this value to accommodate signal-to-noise ratios across the entire experimental image dataset. This threshold value was used to threshold pixels inside the ROI. Pixels with intensity values above the adjusted threshold value were designated as $\mathrm{Iba} 1^{+}$signal. All positive pixels were counted and then divided by the total number of pixels contained within the analysis volume to establish the Iba-positive ratio. For each optic nerve, at least two separate 3D ROIs were established and ana- 
lyzed, and these results were averaged. For final comparison between the mutant and the control, we averaged our results across optic nerves from within a group and used a two-tailed $t$-test to determine significance between groups.

\section{RGC subtype analysis}

Six- and 9-month control and mutant retinas were fixed as described above, and flat-mount IHC was performed to count RGCs. Retinas were washed in PBS ( $3 \times 15$ min) and incubated for $3 \mathrm{~h}$ in blocking solution (5\% donkey serum, $1 \%$ bovine serum albumin, and $0.5 \%$ Triton $\mathrm{X}-100$ in $0.1 \mathrm{M}$ PBS). Retinas were incubated in anti-RBPMS (PhosphoSolutions), anti-melanopsin (Advance Targeting Systems, San Diego, CA), and anti-OPN1-SW (Santa Cruz Biotechnology) antibodies for $2 \mathrm{~d}$ at $4^{\circ} \mathrm{C}$, washed $(6 \times 10$ $\mathrm{min})$, and incubated in secondary antibodies for $3 \mathrm{~h}$ at room temperature. Retinas were washed in PBS $(3 \times 15 \mathrm{~min})$ followed by PB $(1 \times 15 \mathrm{~min})$. They were mounted ganglion cell layer (GCL) up on glass slides with Fluoromount-G (Southern Biotechnology, Birmingham, AL) with special attention to the superior and inferior orientation of the retina. The orientation of the retina (dorsal/superior versus ventral/ inferior leaflets) was confirmed by immunostaining with s-opsin, which is expressed at higher concentration in the ventral (inferior) retina (Applebury et al., 2000). Whole-mount retinas were imaged using a Leica TCS SP5 Confocal Laser Scanning Microscope. For retinas, a tile scan of the entire retina at the outer retinal layers was acquired at $10 \times$ to orient the retina based on the $s$-opsin gradient. Then, $z$-stacks at $1.5-\mu \mathrm{m}$ increments and $x y$-dimension of 0.15 $\mathrm{mm}^{2}$ were acquired through the RGC layer at $40 \times$. Two adjacent but nonoverlapping stacks were acquired $1 \mathrm{~mm}$ from the $\mathrm{ONH}$ in each of the four quadrants of the retina (superior, nasal, inferior, and temporal). Bleed-through was avoided by using a sequential scan setting. Cells were manually counted in Adobe Photoshop CC 2015; only RGCs in which the entire soma profile was shown within the image screen were counted. Only melanopsin ganglion cells with bright staining in which proximal portions of the primary dendrites were visible were counted. Data analysis and statistics were performed using appropriate one- or two-way ANOVA. Tukey's honestly significant difference test was used to assess statistically significant main effects or interactions. Data are considered significant when $p<0.05$.

\section{Results}

\section{Ikbkap is expressed in many types of postmitotic neurons of the retina}

Because patients with FD suffer from blindness, which generally starts in their twenties (Mendoza-Santiesteban et al., 2012, 2014), there is considerable interest in developing treatments to ameliorate blindness and prevent progressive degeneration. The purpose of this study was to generate a model system in which we could identify the retinal cell types affected and ultimately determine the mechanisms causing blindness in FD. Generation of an FD blindness model would also prove powerful for testing potential treatments. Toward this goal, it is critical that we understand the functions and retinal cell types in which
Ikbkap is required. Although there is clinical evidence for retinal degeneration in FD patients (Mendoza-Santiesteban et al., 2014), the expression of Ikbkap and its requirement in the retina have not been investigated.

Toward this end, we first determined the expression pattern of lkbkap in wild-type retinas at various developmental ages using LacZ reporter mice (Ikbkap: $\beta$-gal; George et al., 2013). Retinas at embryonic day 15 (E15; peak of RGC generation), postnatal day 7 (P7), P14 (completion of retinal development), 1 month, and 2 months (adult) were collected, and LacZ staining was performed (Fig. 1A-C). At E15, Ikbkap expression was detected in postmitotic neurons in the GCL but not in retinal progenitors (Fig. $1 A$ ). We did not observe any regional bias or asymmetry in the expression pattern at any developmental stage (Fig. 1A, B). At P14 and older, the mature expression pattern was established: LacZ staining was detected in RGCs, in a subset of cells in the inner nuclear layer (INL), photoreceptor inner segment (IS), and outer plexiform layer (Fig. 1C, 1 month shown). IHC analyses using anti- $\beta$-galactosidase antibody at 1 month showed the same pattern as the LacZ staining (Fig. $1 D$ top) and revealed that all RGCs express Ikbkap, indicated by the colocalization of $\beta$-galactosidase and a pan-RGC marker, RBPMS (Rodriguez et al., 2014; Fig. 1E). In addition, Ikbkap expression was detected in many amacrine cells in both the INL and GCL $\left(\mathrm{AP} 2 \alpha^{+}\right.$or Sox2 ${ }^{+}$; Fig. $1 F, H$, arrowheads) as well as in a subset of bipolar cells (Otx2 ${ }^{+}$ in INL; Fig. 1G, arrows). Interestingly, Sox $2^{+}$Müller glial nuclei did not colocalize with $\beta$-galactosidase (Fig. $1 \mathrm{H}$, arrows), suggesting that Müller glia do not express Ikbkap in the adult retina.

\section{Generation of Ikbkap CKO mice that model FD optic neuropathy}

We generated Ikbkap CKO mice using T $\alpha 1$-Cre, which targets postmitotic neurons (Chaverra et al., unpublished observations; Gloster et al., 1994; Coppola et al., 2004; Coksaygan et al., 2006). To measure Cre expression pattern in the retina, we crossed Ta1-Cre with $\mathrm{mTmG}$ Cre reporter mice (Muzumdar et al., 2007). At E17.5, Cre expression was detected in postmitotic cells in the GCL and optic nerve, but not in retinal progenitors (Fig. $2 A-C$ ). To our surprise, at P10, Cre expression was fairly limited to RGCs, with only a few other retinal neuron types and Müller glia being $\mathrm{Cre}^{+}$(Fig. 2D). In the central $(>0.25 \mathrm{~mm}$ from the $\mathrm{ONH}$ ), temporal, and nasal (1 $\mathrm{mm}$ from the $\mathrm{ONH}$ ) retina, $\sim 90 \%$ of RGCs $\left(\mathrm{RBPMS}^{+}\right)$expressed Cre by P10 without regional bias (Fig. 2E, F). The Cre reporter expression pattern did not change in 1- and 8-month retinas, and there was no increase in $\mathrm{Cre}^{+}$cells compared to P10 retinas (Fig. 2G-K; 1 month images shown). Very few bipolar cells $\left(1.6 \%\right.$ Otx2 ${ }^{+}$cells in INL; Fig. $\left.2 G, J\right)$, photoreceptors (Fig. 2G, K), Müller glia (3.0\% Sox $9^{+}$cells; Fig. $2 \mathrm{H}, \mathrm{J}$ ), or amacrine cells (Fig. $2 \mathrm{G}$ ) expressed the GFP Cre reporter, whereas $89.2 \%$ of RGCs (Fig. 2I, J) expressed Cre at 1 month. At 8 months, the number of $\mathrm{GFP}^{+}$photoreceptors did not differ significantly compared to younger (1 month) retinas (Fig. $2 K$ ). 
A

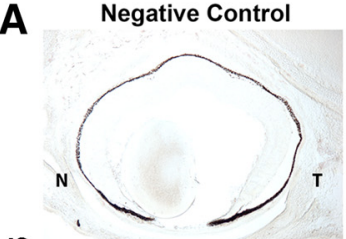

ำ

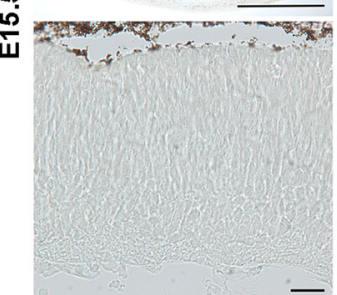

B

P7

C

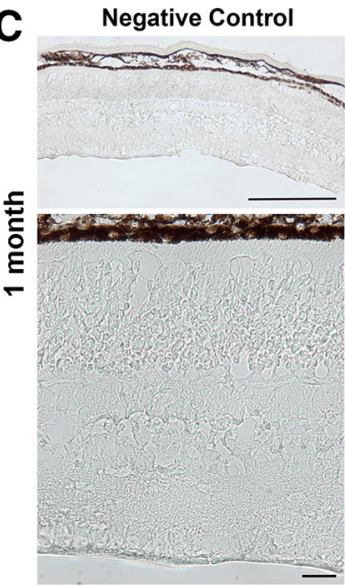

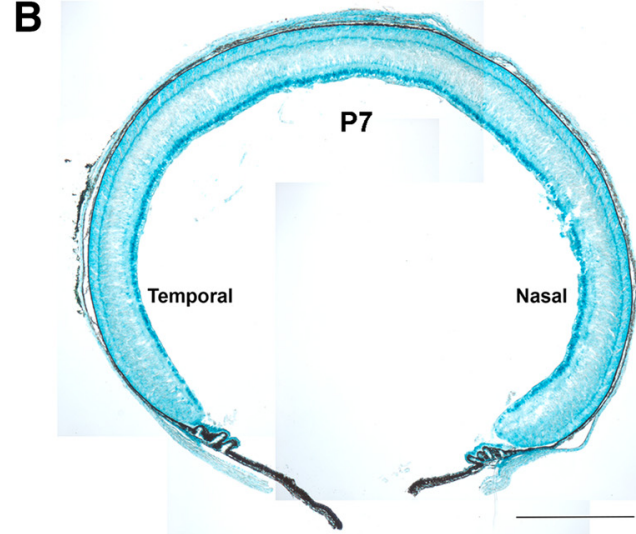

Ikbkap:ß-gal+
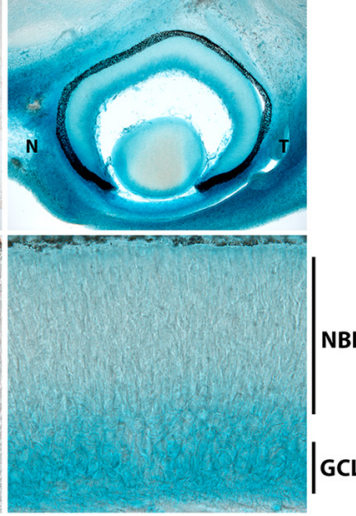

GCL

NBL

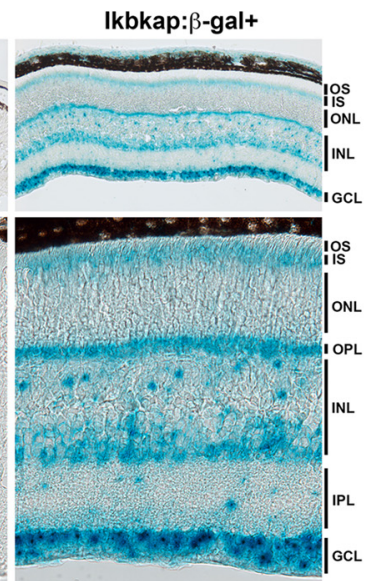

D
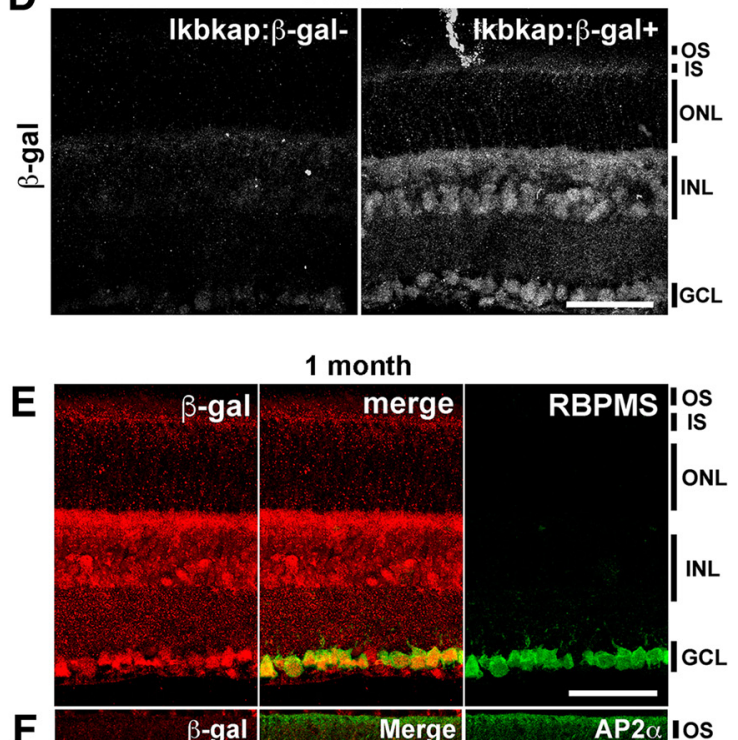

F

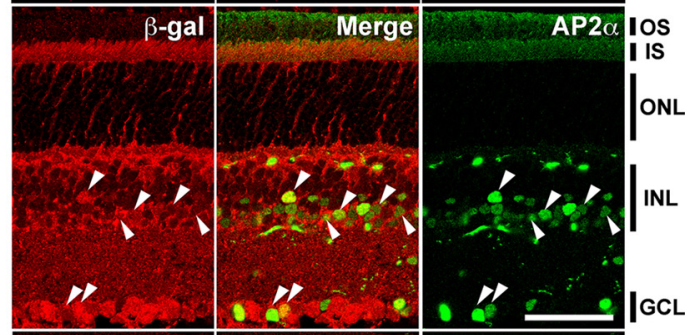

G

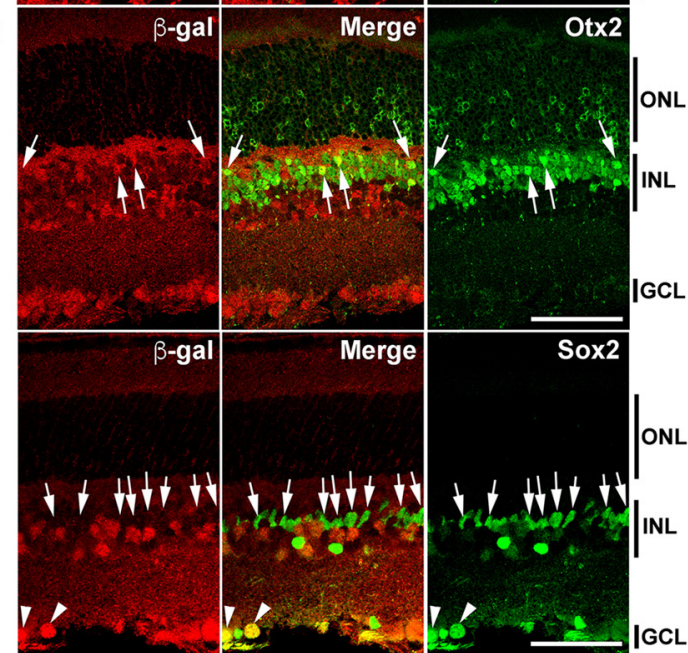

Figure 1. Endogenous Ikbkap expression in the retina. Representative LacZ staining on Ikbkap: $\beta$-gal retina or $\beta$-galactosidase IHC images are shown. A, At E15.5, lkbkap expression was detected in developing RGCs in the GCL. N, nasal; T, temporal. B, P7 retina showed strong expression in the GCL. There was no regional bias or asymmetry in the expression pattern. $\boldsymbol{C}$, At 1 month, RGCs, amacrine cells, subset of bipolar cells, and photoreceptors (IS and outer plexiform layer) expressed IKAP. D, At 1 month, antibody staining showed the same pattern of Ikbkap expression as LacZ staining. $\boldsymbol{E}$, All RGCs (RBPMS ${ }^{+}$, green) expressed Ikbkap (red; bottom). $\boldsymbol{F}$, Many amacrine cells (AP2 $\alpha^{+}$) expressed Ikbkap (red; arrowheads). G, A subset of bipolar cells (Otx2 ${ }^{+}$in INL) expressed Ikbkap (red; arrows). $\boldsymbol{H}$, Müller glial marker Sox2 (green) did not colocalize with $\beta$-gal (red; arrows), suggesting that they do not express Ikbkap. Some of the Sox ${ }^{+}$amacrine cells expressed lkbkap (arrowheads). NBL, neuroblastic layer. Scale bars, $1 \mathrm{~mm}(\boldsymbol{A}$, top), $50 \mu \mathrm{m}$ (A, bottom), $500 \mu \mathrm{m}(\boldsymbol{B}), 250 \mu \mathrm{m}$ (C, top), $25 \mu \mathrm{m}$ (C, bottom), and $50 \mu \mathrm{m}(\boldsymbol{D}-\boldsymbol{H})$.

\section{Loss of lkbkap causes severe degeneration in older CKO retinas}

Because $T \alpha 1$-Cre is expressed in many postmitotic neurons throughout the central and peripheral nervous system, Ikbkap CKO mice die on average by 6 months of age owing to pro- gressive central and peripheral neuropathy as observed in FD patients (Chaverra et al., unpublished observations). However, the phenotype is highly variable between CKOs, and some occasionally survive longer, which allowed us to analyze older $\mathrm{CKO}$ retinas. We assessed the overall retinal morphology of 
A

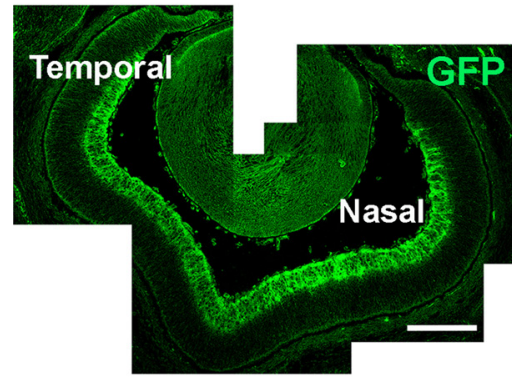

B

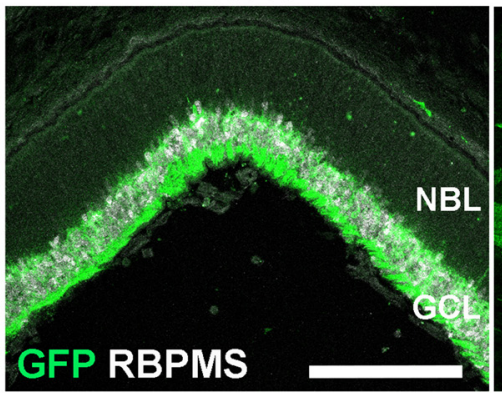

C

E17.5

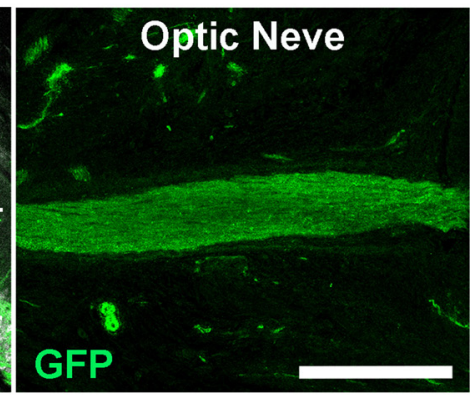

D

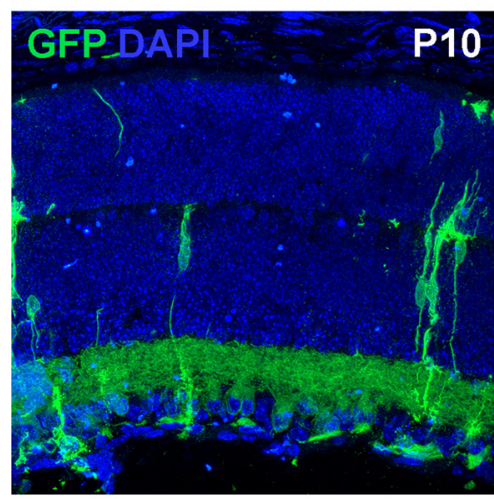

E P10

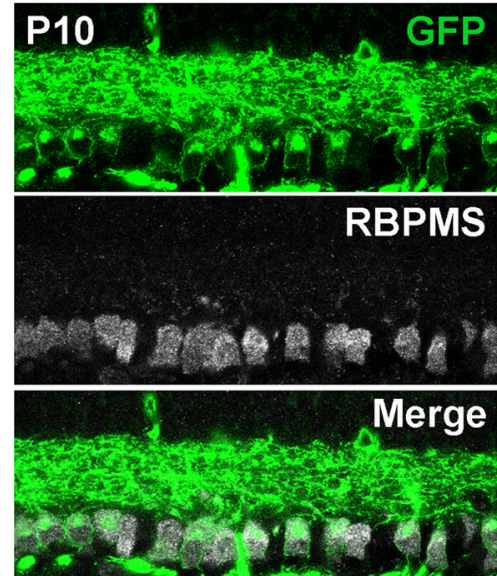

$F$

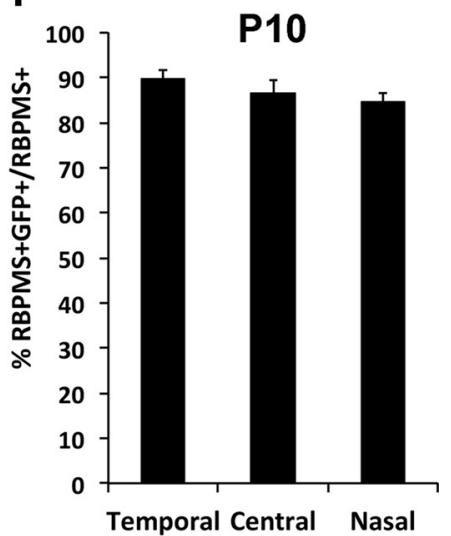

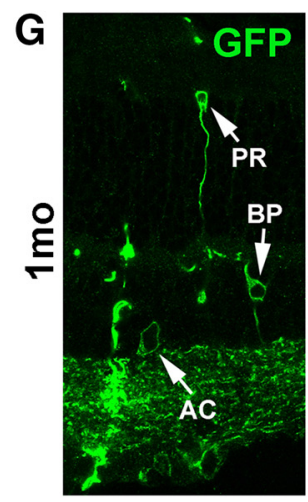
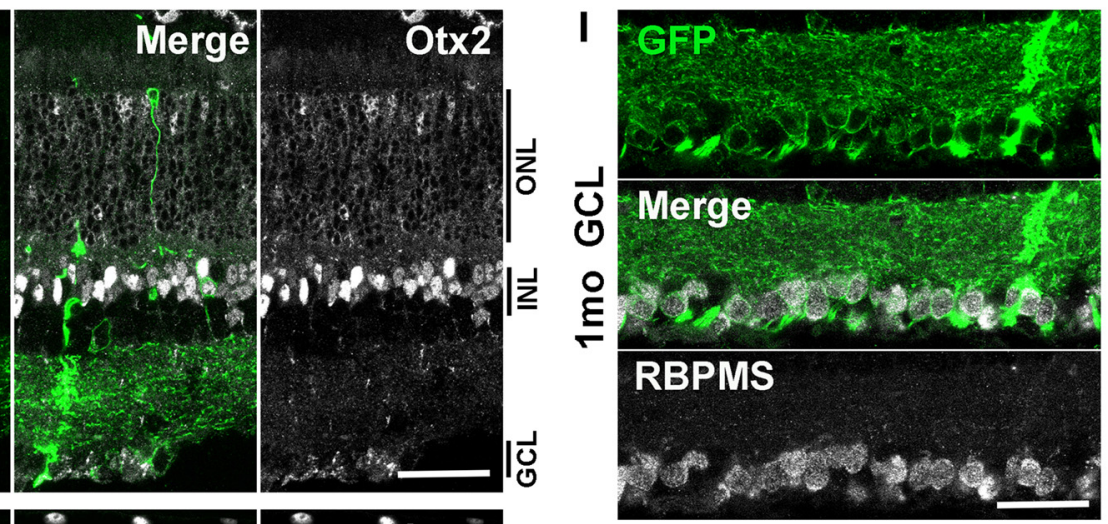

H
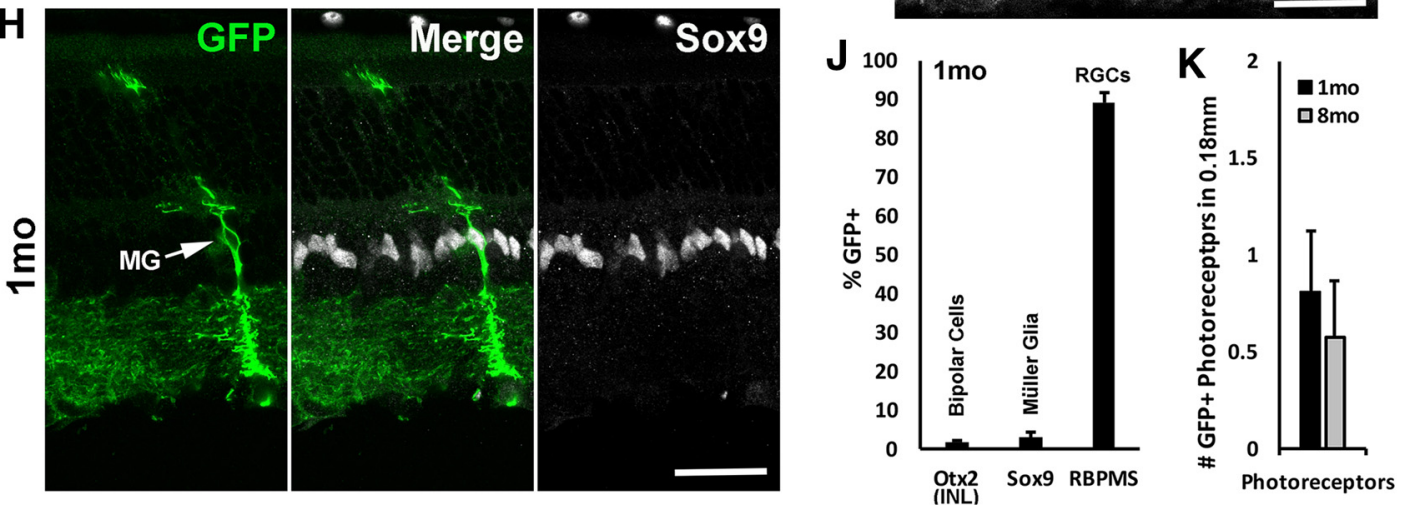

Figure 2. T $\alpha 1$-Cre mice were crossed to $\mathrm{mTmG}$ Cre reporter, and GFP expression was analyzed at E17.5, P10, and 1 and 8 months. $\boldsymbol{A}$ and $\boldsymbol{B}$, At E17.5, Cre expression $\left(\mathrm{GFP}^{+}\right.$) was detected in the GCL without regional bias. GFP colocalized with pan-RGC marker RBPMS (white). $\boldsymbol{C}$, GFP was detected in the optic nerve at E17.5, indicating Cre expression in RGCs. $\boldsymbol{D}$, Very few cells other than RGCs expressed Cre $\left(\mathrm{GFP}^{+}\right)$at P10. E, Most RGCs $\left(\mathrm{RBPMS}^{+}\right)$expressed Cre $\left(\mathrm{GFP}^{+}\right)$at P10. Representative images at the temporal retina are shown. $\boldsymbol{F}$, Approximately $90 \%$ of RGCs expressed Cre by P10, and there was no regional bias. Error bars represent SEM 
continued

$(n=4)$. Central, $>0.25 \mathrm{~mm}$ from $\mathrm{ONH}$; temporal and nasal, $1 \mathrm{~mm}$ from ONH. G-K, Cell type-specific markers were used to analyze Cre expression in the retina at 1 month. Very few bipolar cells (BP; Otx2 ${ }^{+}$in INL; $\left.\mathbf{G}, \boldsymbol{J}\right)$, amacrine cells (AC; $\left.\mathbf{G}\right)$, photoreceptors (PR; $\boldsymbol{G}, \boldsymbol{K})$, or Müller glia (MG; Sox $\left.9^{+} ; \boldsymbol{H}, \boldsymbol{J}\right)$ expressed Cre, whereas Cre expression was detected in $\sim 90 \%$ of RGCs (RBPMS $\left.; \boldsymbol{I}^{+}, \boldsymbol{J}\right)$. Cre-expressing photoreceptor numbers did not increase in older retinas (8 months) compared with 1 month $(\boldsymbol{K})$. Error bars in $\boldsymbol{J}$ and $\boldsymbol{K}$ represent SEM $(n=3)$. NBL, neuroblastic layer. Scale bars, $250 \mu \mathrm{m}(\boldsymbol{A}-\boldsymbol{C})$ and $50 \mu \mathrm{m}(\mathbf{G}-\boldsymbol{I})$.

19-month-old CKO retinas and optic nerves by H\&E staining (Fig. 3). In general, mutant eyes were smaller, retinal layers were disrupted, and the lenses were often absent (Fig. 3A). Many eyes older than 14 months showed immune cells and debris in the vitreous (data not shown). Cross sections of 19-month-old mutant retinas showed obvious photoreceptor degeneration across the retina, with a thinner ONL and an absence of photoreceptor IS and outer segment (OS; Fig. 3B). Optic nerves of 19-month-old mutants were clearly thinner than those of their control littermates, an indication of RGC degeneration (Fig. 3C). In addition, mutant retina displayed rosette formation and dys- lamination of retinal layers (Fig. 3D), as well as Müller glial activation (Fig. $3 E$ ), the hallmarks of retinal degeneration and stress. Whether all or some of these phenotypes were direct or indirect consequences of the loss of Ikbkap in RGCs has yet to be determined.

\section{RGCs are the first cell type to be affected in Ikbkap CKO retinas}

We analyzed 6-month-old mutant retinas for any sign of retinal degeneration. Although mutant eyes were occasionally smaller compared with their littermate controls,

A
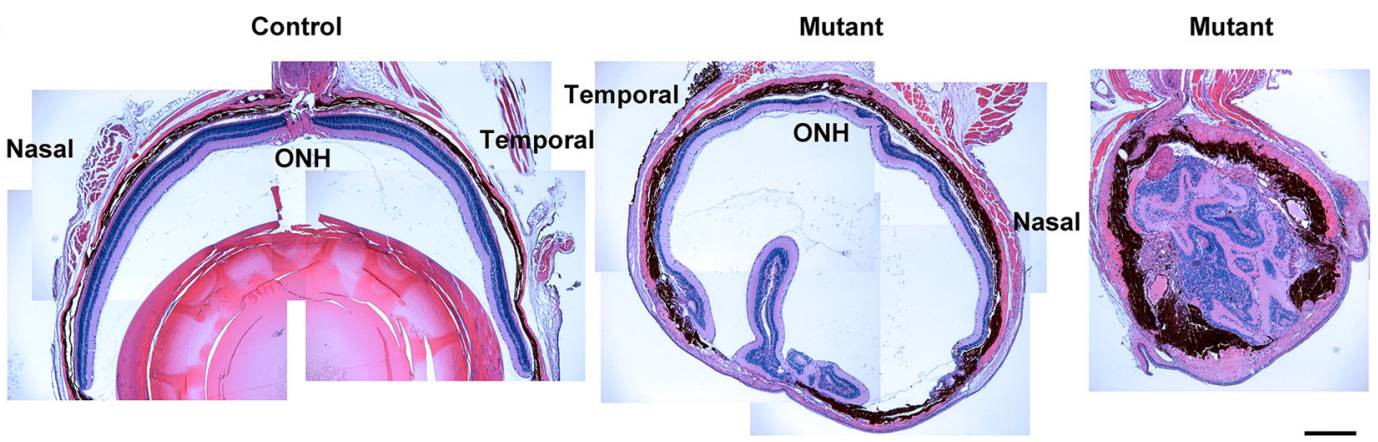

B
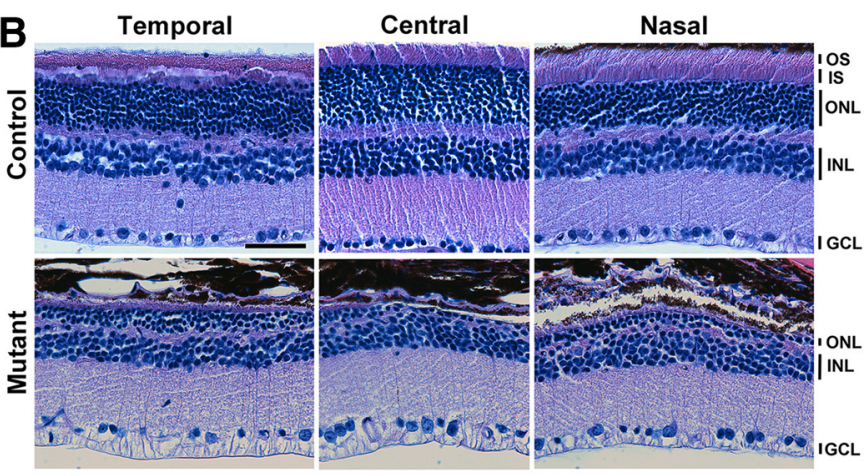

C
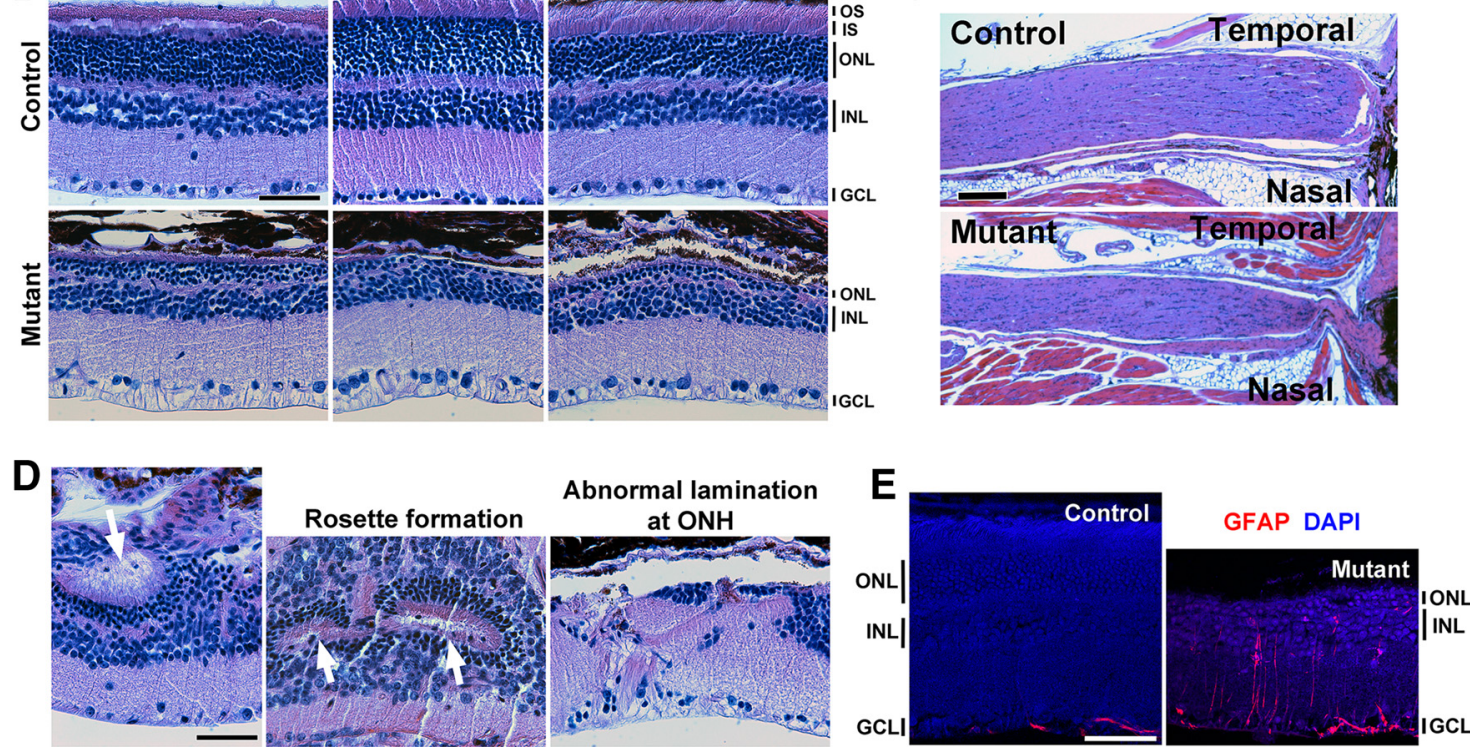

Figure 3. Nineteen-month Ikbkap CKOs displayed severe retinal degeneration. $\boldsymbol{A}$, H\&E staining showing a control and two mutant (CKO) eyes. Mutant eyes were smaller, and lenses were often absent; retinas showed obvious sign of degeneration. $\boldsymbol{B}$, Retinal cross sections at temporal, central, and nasal retinas. Mutant retinas showed clear photoreceptor degeneration, indicated by the thinner ONL and the absence of IS and OS. The number of cells in GCL was reduced. $\boldsymbol{C}$, CKO optic nerves were thinner. $\boldsymbol{D}$, Abnormal retinal structures, such as rosette formation and dyslamination of the layers, were observed in the mutant retinas. $E$, IHC of the GFAP indicated Müller glial activation in the mutant retinas. Scale bars, $250 \mu \mathrm{m}(\boldsymbol{A}), 50 \mu \mathrm{m}(\boldsymbol{B}, \boldsymbol{D}$, and $\boldsymbol{E})$, and $100 \mu \mathrm{m}(\boldsymbol{C})$. 
A
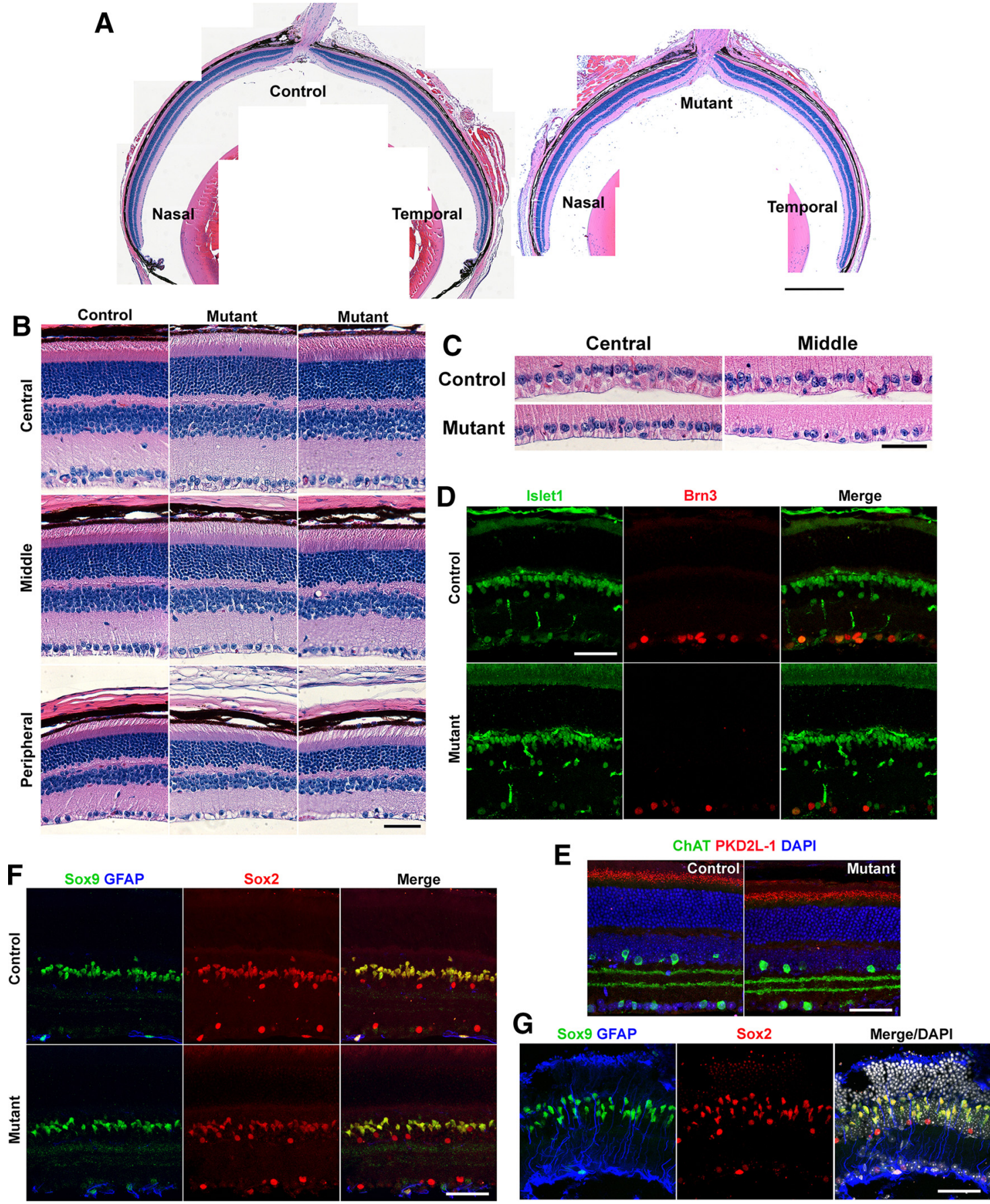

Figure 4. Six-month Ikbkap CKO retinas were grossly normal except for the reduction in RGCs. $\boldsymbol{A}$, H\&E staining showing control and mutant (CKO) eyes. The mutant eyes at 6 months appear normal. $\boldsymbol{B}$, Retinal cross sections at central $(>0.25 \mathrm{~mm}$ from ONH), middle $(1 \mathrm{~mm}$ from $\mathrm{ONH})$, and peripheral $(1.75 \mathrm{~mm}$ from $\mathrm{ONH})$ retinas in the temporal hemisphere. Retinal structure of the mutant was grossly normal, except for the reduction in cell number in the GCL that is apparent toward the peripheral retinas. $\boldsymbol{C}$, Reduction in cell number was observed in the mutant GCL at $1 \mathrm{~mm}$ from the $\mathrm{ONH}$ (middle). Images of the temporal retina are shown. $\boldsymbol{D}$, Mutant retinas showed reduced numbers of RGC marker, Brn3 (red). Islet1 (green) IHC showed normal cholinergic amacrine and optic nerve bipolar cells. $\boldsymbol{E}$, Choline acetyltransferase (green) IHC showed normal number and structure of cholinergic amacrine cells. PKD2L-1 (red) IHC indicated normal photoreceptor cilia structure. $\boldsymbol{F}$, Müller glial marker Sox9 (green), Sox2 (red), and GFAP (blue) showed normal, nonactivated Müller glia in the mutant retinas. G. Because of variability in the phenotype, degenerating mutant retinas were occasionally observed at 6 months. In these retinas, Müller glia were activated (GFAP upregulation), and photoreceptor rosettes were seen. $\boldsymbol{D}-\mathbf{G}$, Images represent $1 \mathrm{~mm}$ from the $\mathrm{ONH}$ at the temporal retina. Scale bars, $250 \mu \mathrm{m}(\boldsymbol{A})$ and $50 \mu \mathrm{m}(\boldsymbol{B}-\mathbf{G})$. 

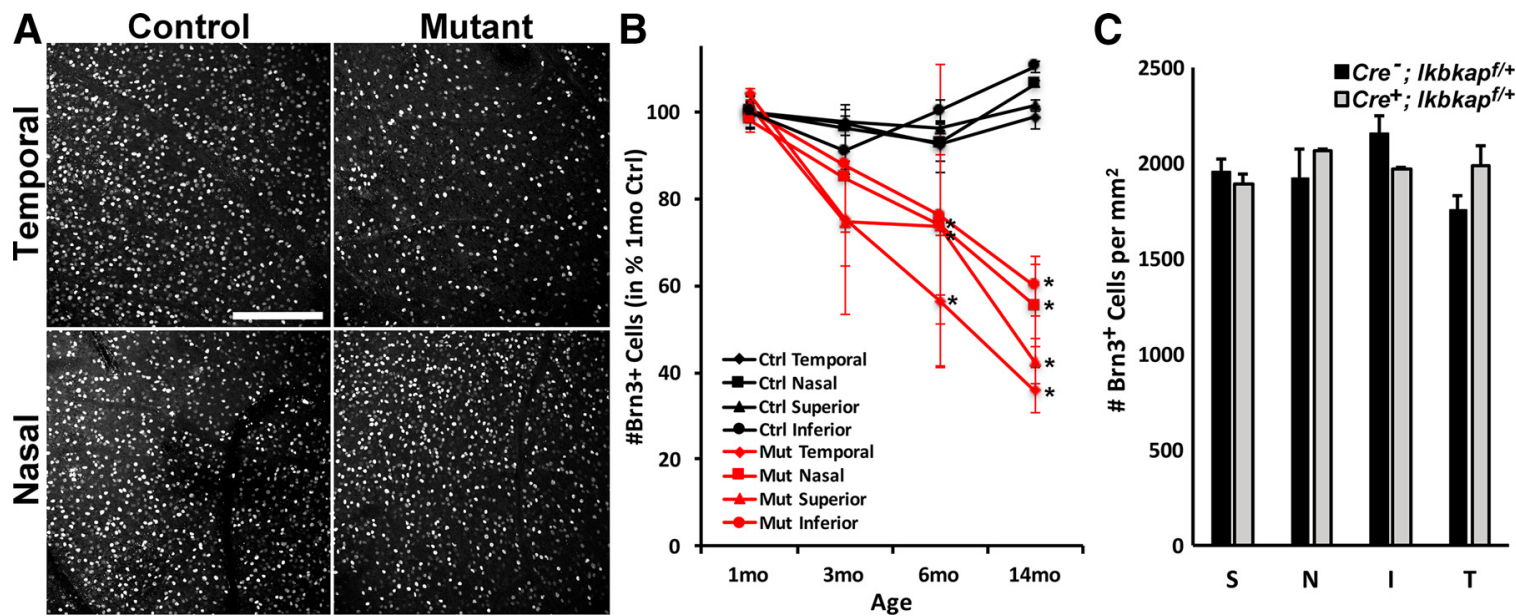

Figure 5. Loss of Ikbkap in RGCs caused slow, progressive RGC degeneration. $\boldsymbol{A}$, Representative Brn3 (RGC marker) staining in the temporal and nasal retinas at 6 months. Images were taken at $1 \mathrm{~mm}$ from ONH. B. The number of Brn3 ${ }^{+} \mathrm{RGCs}$ in $/ \mathrm{kbkap} \mathrm{CKO}$ (mutant) retinas was counted. Significant loss of Brn3 ${ }^{+}$cells was observed in temporal and superior retinas at 6 months, which progressively spread into entire retinas by 14 months. $\boldsymbol{C}$, The numbers of $\mathrm{Brn}^{+}$RGCs were counted in each quadrant of 6- to 8-month-old $\mathrm{Cre}^{-} ; \mathrm{lkbkap}{ }^{f /+}$ and $\mathrm{Cre}^{+} ; \mathrm{lkbkap}{ }^{f /+}$ retinas at $1 \mathrm{~mm}$ from the $\mathrm{ONH}$. There was no significant decrease in the number of RGCs in

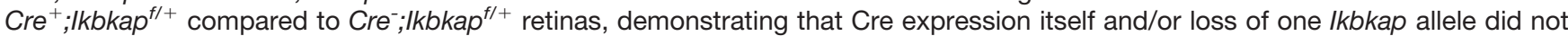
cause RGC degeneration. S, superior; N, nasal; I, inferior; T, temporal. Error bars represent SEM $(n=\geq 4$ per point for $\boldsymbol{B} ; n=3$ for C). $* p<0.05$ with $t$-test. Scale bars, $100 \mu \mathrm{m}(\boldsymbol{A})$.

overall morphology of the eye appeared grossly normal (Fig. 4A). Analysis of 6 -month retinal cross sections by H\&E staining showed no abnormal lamination or thickness of retinal layers in the mutants (Fig. 4B). However, loss of cells in the middle $(1 \mathrm{~mm}$ from the $\mathrm{ONH})$ to peripheral retinas was observed in the RGC layer of the mutant retina (Fig. 4B, C). IHC analyses revealed reduction in $\mathrm{Brn}^{+}$ RGCs in the mutants (Fig. $4 D$, red; see below for quantitation), whereas staining for Islet1 (a marker for cholinergic amacrine, optic nerve bipolar, and RGCs; Fig. 4D, green) and choline acetyltransferase (a marker for cholinergic amacrine cells; Fig. $4 E$, green) showed comparable cell numbers, morphology, and location between the mutant and littermate controls. Sox ${ }^{+} / \mathrm{Sox}^{+}$Müller glial nuclei were localized in a single layer in the INL, and the activation marker GFAP was not observed in either mutant or control retinas (Fig. 4F). The number of photoreceptor nuclei appeared normal (Fig. 4B), and the photoreceptor cilia marker PKD2L-1 showed a normal pattern in the mutant (Fig. 4F). Because of the high variability in mutant phenotypes, we occasionally observed severe retinal degeneration as early as 6 months (Fig. 4G), and those retinas had photoreceptor rosette formation, Müller glial activation (GFAP upregulation), and loss of RGCs, as seen in older mutant retinas (Fig. 3).

\section{Loss of Ikbkap in RGCs causes slow, progressive RGC degeneration and optic nerve inflammation}

Because $T \alpha 1-C r e$ is expressed predominantly in RGCs in the retina (Fig. 2) and human FD patients show RGC defects (Mendoza-Santiesteban et al., 2012, 2014), we tracked spatial and temporal changes in RGCs in the $T \alpha 1$-Cre Ikbkap CKO retinas. Retinas were harvested at 1 , 3,6 , and 14 months of age, and the number of RGCs 1 $\mathrm{mm}$ from the $\mathrm{ONH}$ in temporal, nasal, superior, and infe- rior retinas were counted using the RGC nuclear marker Brn3 (Fig. 5). At 1 month, the mutant and control retinas contained similar numbers of $\mathrm{Brn}^{+}$RGCs in all quadrants, suggesting that RGC development was not affected by the absence of Ikbkap. In contrast, by 6 months, a significant loss of RGCs was observed in the mutant retinas. The reduction in RGCs was greatest in the temporal retina $(\sim 50 \%$ reduction; Fig. $5 A, B)$, which corresponds to the clinical observation of FD patients (Mendoza-Santiesteban et al., 2012, 2014). Superior and inferior mutant retinas had an approximately $30 \%$ reduction in RGCs compared with control retinas at 6 months. RGC degeneration continued with age, and by 14 months, panretinal loss of RGCs was observed, with the most dramatic loss of RGCs, greater than $60 \%$, in the temporal retina. To rule out a possibility that Cre expression itself causes RGC degeneration, the number of $\mathrm{Brn}^{+}$RGCs in 6- to 8-month $\mathrm{Cre}^{-} ; \mathrm{lkbkap}{ }^{f /+}$ and $\mathrm{Cre}^{+} ; \mathrm{Ikbkap}^{f /+}$ retinas was counted at $1 \mathrm{~mm}$ from the $\mathrm{ONH}$ (Fig. $5 C$ ). The results showed there was no loss of RGCs, indicating that neither Cre expression itself nor loss of one Ikbkap allele causes RGC degeneration. We conclude from these results that in the absence of Ikbkap, RGCs undergo a slow but progressive degeneration, with the same spatial pattern as observed in FD patients.

We also analyzed the optic nerves (RGC axon bundle) of 6- and 9-month mutant and control mice. Although the circumference of the optic nerves was slightly smaller in both 6- and 9-month mutant optic nerves compared with controls, the difference was not significant (data not shown). A microglial/macrophage marker, lba1 (Ito et al., 2001), showed no difference in microglial number and morphology in the 6-month mutant and control optic nerves (data not shown). However, by 9 months, the optic nerves of mutant animals demonstrated evidence of in- 

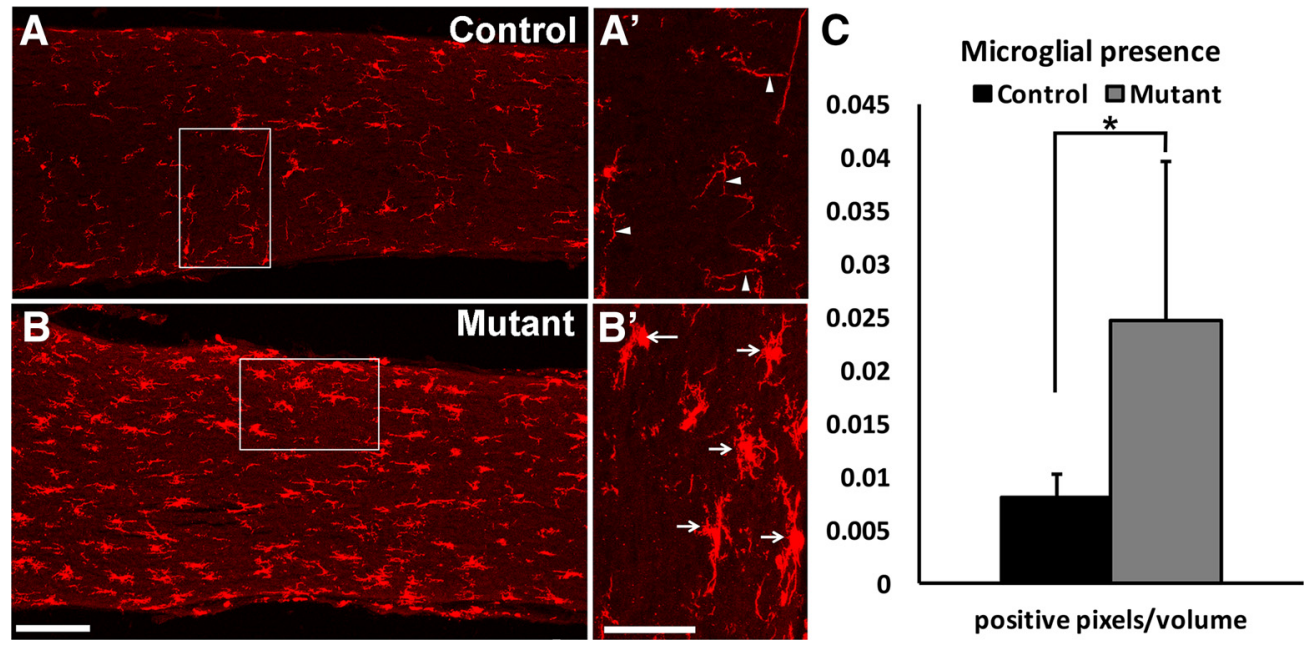

Figure 6. Activation of microglia was observed in the Ikbkap CKO optic nerves. Maximum-intensity z-stack projections of longitudinal optic nerve sections were stained with microglial/macrophage marker lba1 in 9-month control $(\boldsymbol{A})$ and mutant $(\boldsymbol{B})$ optic nerves. Representative images are shown. Microglia in control optic nerves had thin ramified branches (arrowheads in $\boldsymbol{A}$ inset); microglia in mutant optic nerves had ameboid morphology (arrows in $\boldsymbol{B}$ ) indicative of inflammatory response. White boxes in $\boldsymbol{A}$ and $\boldsymbol{B}$ indicate areas imaged at higher magnification in $\boldsymbol{A}$ and $\boldsymbol{B}$, respectively. $(\boldsymbol{C})$ The number of lba1-positive pixels that met the criteria was counted and divided by the total number of pixels in the volume of the area, as described in Materials and Methods. The data show that mutant microglia occupied increased areas in the optic nerve, suggesting the presence of inflammatory response. $* p=0.05$ with a two-tailed $t$-test ( $n=6$ for control and $n=5$ for mutant). Scale bars, $100 \mu \mathrm{m}(\boldsymbol{A}$ and $\boldsymbol{B})$ and $50 \mu \mathrm{m}(\boldsymbol{A}$ and $\boldsymbol{B})$

flammation (Fig. 6; Ito et al., 2001). Whereas control optic nerves showed microglia with thin ramified branches, mutant optic nerves had microglia with ameboid morphology (Fig. 6A, B). Our analysis shows increased infiltration of activated microglia in the optic nerves of mutant mice (Fig. 6C)

\section{Melanopsin ${ }^{+}$RGCs are resistant to degeneration caused by the absence of Ikbkap}

Although many mature mouse RGCs (80\%-85\%) are known to be $\mathrm{Brn3}^{+}$(Brn3a, Brn3b, and/or Brn3c) and Brn3 is an established nuclear marker for RGCs (Xiang et al., 1995; Nadal-Nicolas et al., 2009; Galindo-Romero et al., 2011), we also quantified the number of RBPMS ${ }^{+}$RGCs, since the RBPMS antibody selectively and exclusively labels all RGCs (Rodriguez et al., 2014). We immunostained whole-mounted retinas at 6 and 9 months of age and counted $\mathrm{RBPMS}^{+}$cells $1 \mathrm{~mm}$ from the optic nerve disk in the superior, nasal, inferior, and temporal retina. In 6-month mutant retinas, we observed a $20 \%-30 \%$ reduction in RGCs in the superior and temporal retina $(p=0.01$ and 0.02 , respectively; Fig. $7 A$ ). There was temporalsuperior bias in total $\left(\mathrm{RBPMS}^{+}\right)$RGC loss, similar to $\mathrm{Brn3}^{+}$RGC degeneration (Fig. 5). In 9-month mutant retinas, more widespread reduction (30\%-35\% decrease) in RGCs was observed; reduction in nasal, inferior, and temporal retinas were significant $(p=0.02,0.03$, and 0.02 , respectively; Fig. $7 B, C$ ). RGC counts were highly variable between mutants at the same age, possibly because of variability in Cre penetrance. We also immunostained using antimelanopsin antibody (Fig. 7D), which is known to label M1-M3 subtypes of intrinsically photosensitive RGCs (ipRGCs). ipRGCs express the photopigment melanopsin and are photosensitive to light independently of rods and cones (Berson et al., 2002; Estevez et al., 2012). Interestingly, we did not observe a reduction in melanopsin ${ }^{+}$RGC in either 6- or 9-month mutant retinas (Fig. 7E; 6-month data not shown). Cre reporter analysis showed that melanopsin ${ }^{+}$ipRGCs were $\mathrm{GFP}^{+}$at P10 (Fig. $7 F$, indicating Cre expression in this RGC subtype. In addition, our endogenous Ikbkap expression analysis of the retina at 1 month also showed that all the RGCs $\left(\mathrm{RBPMS}^{+}\right)$expressed Ikbkap $\left(\beta-\mathrm{gal}{ }^{+}\right.$; Fig. 1E). These results suggest that melanopsin ${ }^{+}$RGCs are resistant to degeneration in the absence of $/ k b k a p$.

\section{RGC loss is followed by photoreceptor degeneration in Ikbkap CKO retinas}

Because older mutant retinas show clear signs of photoreceptor degeneration (Fig. 3), we quantified the number of photoreceptors in 6-, 9-, and 14-month mutant and control retinas (Fig. 8). The number of photoreceptors lying in a single column spanning the ONL was counted in H\&E-stained retinal cross sections as described previously (LaVail et al., 1992; Ueki et al., 2008; Chollangi et al., 2009). Counts were made at $0.25-\mathrm{mm}$ intervals beginning at the $\mathrm{ONH}$ and toward both the temporal and nasal retinal hemispheres (Fig. $8 A, C, E$ ). At 6 months, mutant retinas had similar numbers of rows of photoreceptor nuclei in the ONL across the retina, and photoreceptor IS and OS showed normal morphology (Fig. 8A, B). By 9 months, the temporal retina of the mutants showed slight but significant reduction in photoreceptor nuclei, indicative of photoreceptor degeneration (Fig. 8C). We also observed dyslamination of ONL at temporal peripheral $(>1.5 \mathrm{~mm}$ from $\mathrm{ONH}$ ) retinas of mutants, with the ectopic presence of photoreceptor nuclei in the outer plexiform layer (Fig. 8D, arrowheads). By 14 months, panretinal 


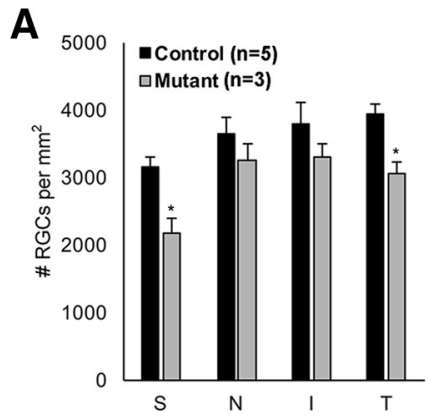

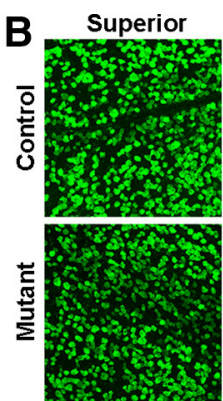
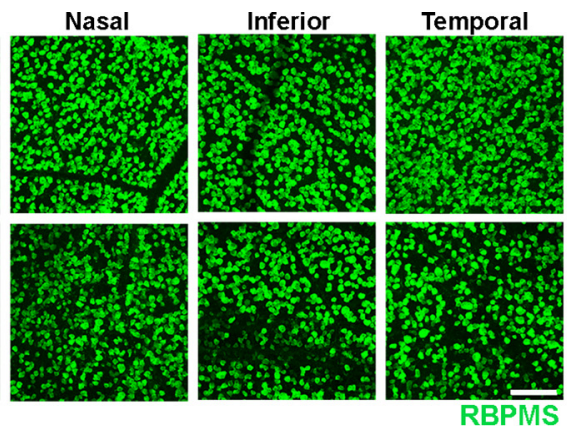

RBPMS

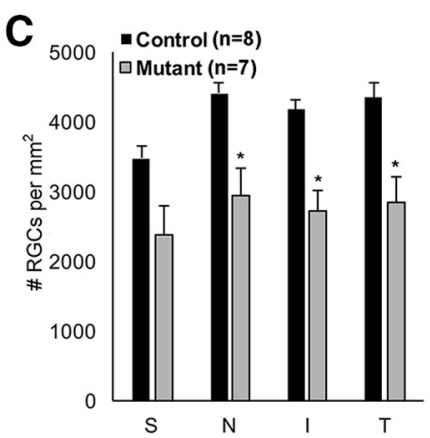

F

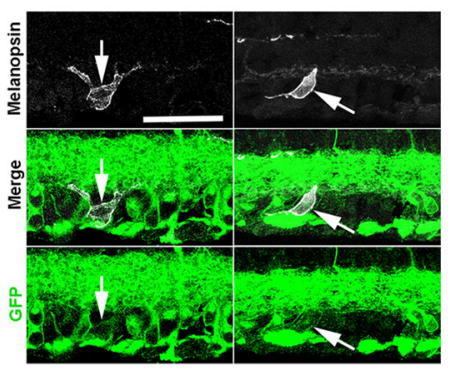

Figure 7. Melanopsin ${ }^{+}$ipRGCs were resistant to degeneration. All images were taken at $1 \mathrm{~mm}$ from the $\mathrm{ONH}$, and numbers of $\mathrm{RBPMS}^{+}$(total RGC marker) or melanopsin ${ }^{+}$(ipRGC marker) cells were counted manually in superior (S) nasal (N), inferior (I), and temporal (T) leaflets. $\boldsymbol{A}$, At 6 months, the mean number of RGCs was significantly lower for mutant mice in superior and temporal retinas ( $p=0.01$ and 0.02 with ANOVA and Tukey's honestly significant difference test). $\boldsymbol{B}$, Representative RBPMS labeling of the 9-month control and mutant retinas. $\boldsymbol{C}$, At 9 months, the mean number of RGCs was significantly lower for mutant mice in nasal, inferior, and temporal retinas $(* p=0.02,0.03$, and 0.02 with ANOVA and Tukey's honestly significant difference test). $\boldsymbol{D}$, Representative melanopsin labeling of 9 -month control and mutant retinas. $\boldsymbol{E}$, At 9 months, there was no significant difference in ipRGC counts between control and mutant retinas. $\boldsymbol{F}$, Cre expression in melanopsin ${ }^{+}$RGCs was analyzed in T $\alpha 1-C r e ; m T m G$ Cre reporter retinas at $\mathrm{P} 10$. Ten melanopsin ${ }^{+}$cells were found in three different Cre reporter retinas, and all 10 were GFP $^{+}$, suggesting that ipRGCs express Cre. Two representative cells are shown (arrows). Error bars in $\boldsymbol{A}, \boldsymbol{C}$, and $\boldsymbol{E}$ represent SEM. Scale bars, $100 \mu \mathrm{m}$ $(\boldsymbol{B}$ and $\boldsymbol{D})$ and $50 \mu \mathrm{m}(\boldsymbol{F})$.

photoreceptor degeneration was observed: on average, the number of rows of photoreceptor nuclei was reduced by $30 \%-40 \%$ across mutant retinas compared with controls (Fig. 8E). The extent of photoreceptor loss varied between mutants, and some mutant retinas displayed severe photoreceptor degeneration with no IS and OS (Fig. 8F). We speculate that this photoreceptor degeneration in our Ikbkap CKO retinas is an indirect consequence of Ikbkap loss in cell types other than photoreceptors, since T $\alpha 1$-Cre expression is nearly absent in photoreceptors in both young and older retinas (Fig. 2A, K).

\section{Discussion}

Familial dysautonomia is an autosomal recessive congenital neuropathy caused by an intronic mutation in IKBKAP, which encodes the protein IKAP (also known as ELP1). Although one of the major adversities that affects FD patient quality of life is progressive blindness, and there is great interest in developing treatments to ameliorate and prevent progressive blindness in the FD community, development of model systems and the pathophysiological mechanisms underlying the loss of vision have not been the focus of any study. We developed and characterized the retinal pheno- type of a new mouse model of FD, in which Ikbkap is disrupted in postmitotic neurons (To1-Cre Ikbkap CKO). To1-Cre Ikbkap CKO mice display many hallmarks of FD symptoms such as small stature, kyphosis, and gait disturbances and typically die by 6 months because of progressive neurodegeneration (Chaverra et al., unpublished

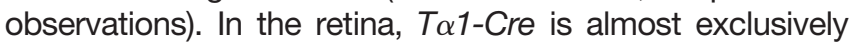
expressed in the RGCs, and deletion of Ikbkap in RGCs initially causes slow, progressive loss of RGCs and inflammation in the optic nerve. Interestingly, the RGC loss is subtype specific, with melanopsin ${ }^{+}$RGCs being resistant to degeneration. In addition, the RGC loss shows regional bias, initiating from the temporal retina followed by spreading throughout the retina. The loss of RGCs is subsequently followed by progressive photoreceptor degeneration, glial activation, and disruption of retinal layers. Because the $/ \mathrm{kb}$ kap gene is broadly expressed throughout the nervous system in both mice and humans (Mezey et al., 2003), and our Ta1-cre was active in many neuronal populations outside of the retina in both the central and peripheral nervous system (Chaverra et al., unpublished observations), we cannot conclude whether the RGC deficits observed in both FD patients and this mouse model were due to direct or indirect consequences of lkbkap loss in the retina. 

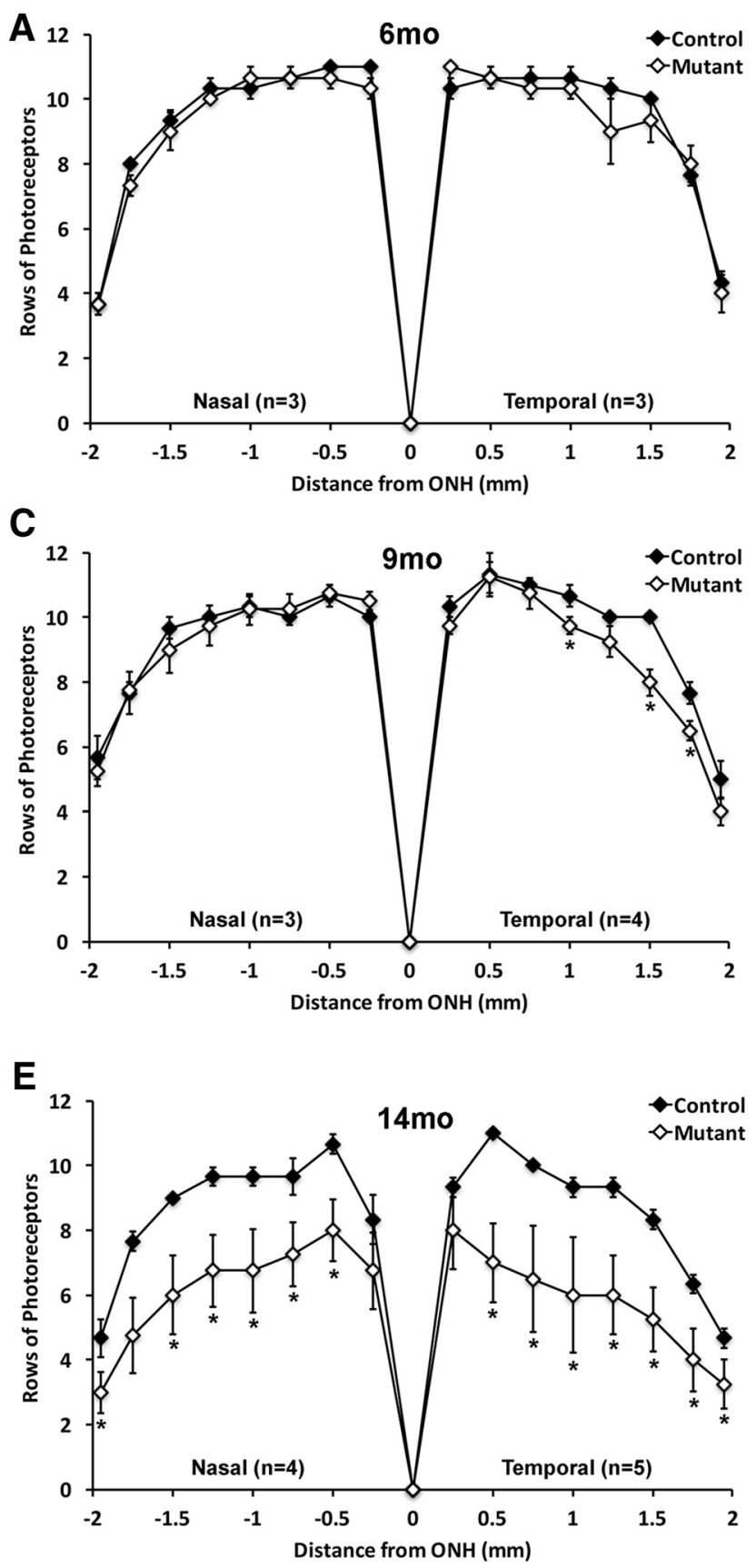
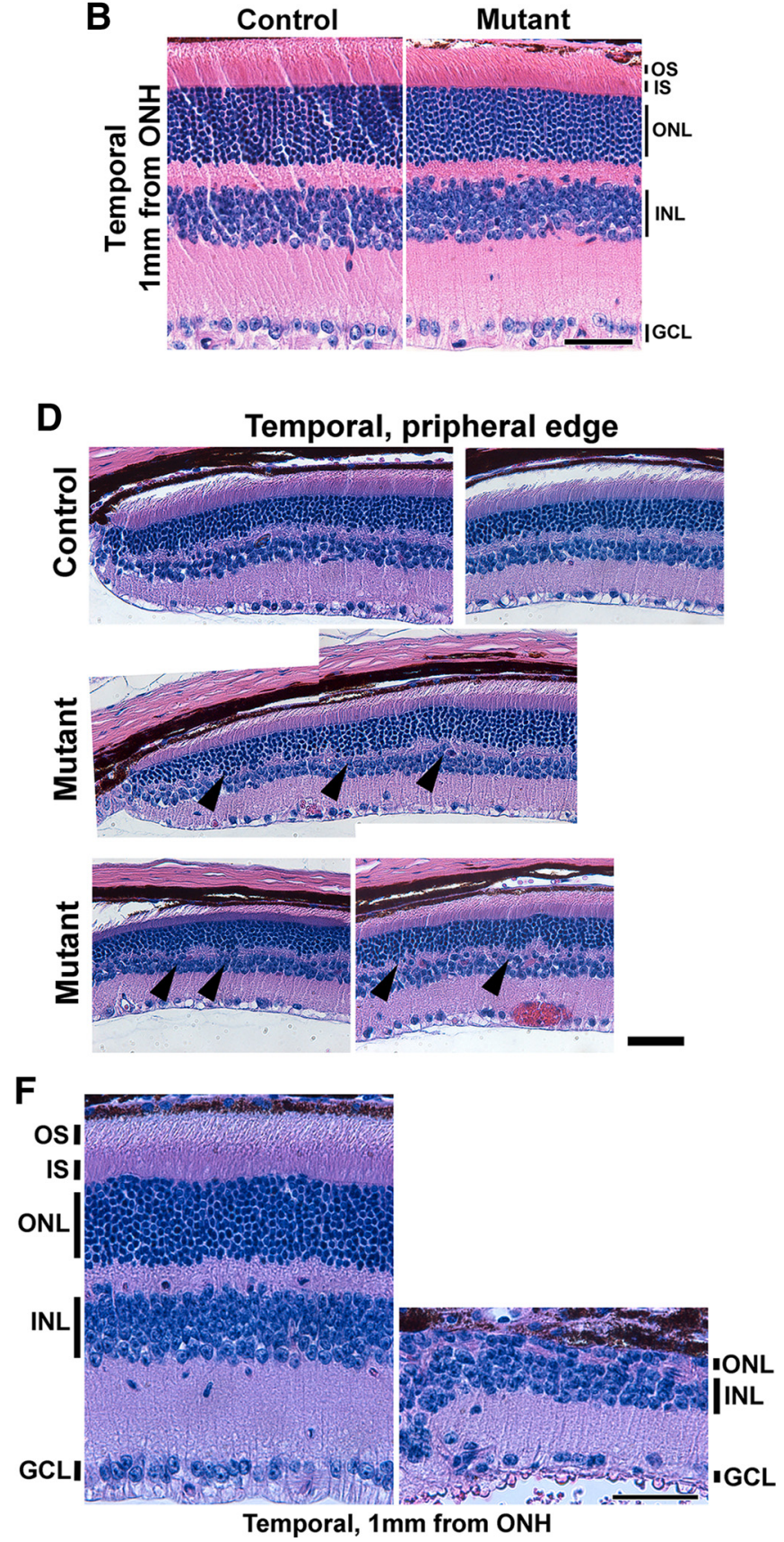

Figure 8. Photoreceptor degeneration was observed in Ikbkap CKO retinas. The number of rows of photoreceptor nuclei in the ONL was counted at $0.25 \mathrm{~mm}$ from the optic nerve in the temporal and nasal retinas at 6 months $(\boldsymbol{A}), 9$ months $(\boldsymbol{C})$, and 14 months $(\boldsymbol{E})$. H\&E-stained cross sections. $\boldsymbol{A}$ and $\boldsymbol{B}$, At 6 months, no sign of photoreceptor degeneration was observed. $\boldsymbol{C}$ and $\boldsymbol{D}$, At 9 months, significant loss of photoreceptors and disorganization of ONL (arrowheads) in the mutant temporal and peripheral retinas were observed. $\boldsymbol{E}$ and $\boldsymbol{F}$, At 14 months, the number of rows of photoreceptor nuclei was clearly reduced across the retina. In addition, photoreceptor IS and OS were absent. Error bars in $\boldsymbol{A}, \boldsymbol{C}$, and $\boldsymbol{E}$ represent SEM (*p $<0.05$ with $t$-test). Scale bars, $50 \mu \mathrm{m}(\boldsymbol{B}, \boldsymbol{D}$, and $\boldsymbol{F})$.

FD is characterized by both developmental and progressive adult neuropathies. Several mouse models of FD have demonstrated that Ikbkap is required for PNS development (Dietrich et al., 2011; Hunnicutt et al., 2012; George et al., 2013; Abashidze et al., 2014; Jackson et al., 2014). We have previously shown, in another CKO FD mouse model in which deletion of $/ k b k a p$ was restricted to the neural crest lineage, that sensory and sympathetic neurons died by caspase 3- and p53-mediated apoptosis during development (George et al., 2013). In the present study, we demonstrated that $/ \mathrm{kbkap}$ is expressed in retinal neurons in the GCL as early as E15.5 (Fig. 1A). In T 1 1-Cre Ikbkap CKO retinas, Cre expression was detected in cells in the GCL by E17.5 (Fig. $2 A-C$ ); however, we did not 
observe an abnormal number or morphology of RGCs in the mature retina at 1 month (Fig. 5). These results suggest that Ikbkap is not required for RGC development.

Visual impairment in FD patients frequently begins at an early age and can progress to legal blindness by their thirties. Until recently, the blindness was thought to be a consequence of inadequate sympathetic and sensory innervation of the eye, since a hallmark of the disease is reduced function of the sensory and autonomic nervous systems (Goldberg et al., 1968; Liebman, 1968; Gold-von Simson and Axelrod, 2006). Although mild to moderate corneal opacities are observed in most eyes of FD patients, none of the eyes had opacities too dense to prevent retinal examinations through the cornea (MendozaSantiesteban et al., 2014). Many older CKO eyes displayed mild corneal opacities as well (data not shown). Strikingly, recent clinical studies have revealed that FD patients show decreased visual acuity, poor color vision and central visual field loss, temporal optic nerve pallor, and delay in visual evoked potentials due to loss of RGCs (Mendoza-Santiesteban et al., 2012, 2014). Optical coherence tomography analysis of FD patients showed that their retinas displayed loss of the retinal nerve fiber layer, a sign of RGC loss, predominantly in the temporal retina, and the loss was greatest in older FD patients (MendozaSantiesteban et al., 2014). CKO retinas showed phenotypes identical to those of FD patients: progressive RGC loss that affects the temporal retina more severely than the nasal retina (Fig. 5). We also observed optic nerve inflammation (Fig. 6), photoreceptor degeneration (Fig. 8), and disruption of retinal layers (Fig. 3). Whether FD patients also experience these phenotypes has not been reported to date. Understanding the complete course of retinal degeneration, including retinal cell types affected in the absence of $I \mathrm{kbkap}$, is essential in the selection of therapeutic targets to prevent blindness in FD.

Two other retinal disorders, Leber hereditary optic neuropathy (LOHN) and dominant optic atrophy (DOA), share remarkably similar retinal phenotype and disease progression with FD patients and our CKO mice. LOHN and DOA are also characterized by loss of vision due to slow, progressive RGC degeneration, with the more metabolically active temporal RGCs being the first to be affected (Newman and Biousse, 2004; Chevrollier et al., 2008; Zanna et al., 2008; Carelli et al., 2009; Kirches, 2011; Yu-Wai-Man et al., 2014). Interestingly, both of these RGC disorders are considered mitochondrial diseases: the genes that are mutated function in mitochondria. Yu et al. (2012) developed a LOHN model in which the mice carried a mutation in NADH dehydrogenase subunit 4 in the retina. Retinal phenotypes of 1-year-old LOHN retinas were remarkably similar to those of $F D$ retinas in the present study: all mutant animals display RGC degeneration, and some also show disruption of retinal layers as well as loss of neurons other than RGCs (Yu et al., 2012). This similarity in phenotype may indicate that the demise of retinal neurons in FD may also result from pathological processes shared with LOHN and DOA-perturbations in mitochondrial function. In support of this hypothesis, a recent study in yeast shows that wobble uridine modifi- cation by the Elongator complex, which includes IKAP/ ELP1, is essential for mitochondrial function under stress (Tigano et al., 2015), further suggesting perturbations in mitochondrial function in FD neurons. Future studies in our FD retinal models will also be investigating mitochondrial function.

A growing body of literature shows that ipRGCs are resistant to injury or degeneration in many diseases compared with conventional RGCs (La Morgia et al., 2011; Feigl and Zele, 2014; Cui et al., 2015). ipRGCs are shown to survive after optic nerve injury or transection in rats and mice (Robinson and Madison, 2004; Li et al., 2008; Perez de Sevilla Muller et al., 2014), although the mechanism of cell survival is unknown. ipRGCs are also protected from $\mathrm{N}$-methyl-D-aspartate-induced excitotoxicity in mice (DeParis et al., 2012). In patients with mitochondrial neuropathies, including LOHN and DOA, ipRGCs survive even in the presence of extensive loss of conventional RGCs ( $\mathrm{La}$ Morgia et al., 2010). The pupillary light reflex, which requires functional ipRGCs (Chen et al., 2011), is also spared in these patients (Moura et al., 2013). Again, the mechanisms for ipRGC survival in these mitochondrial neuropathies are not understood. Several hypotheses have been presented, including a neuroprotective role for melanopsin itself, neuroprotection via high levels of pituitary adenylate cyclase-activating polypeptide expressed in ipRGCs, or unique properties of mitochondrial metabolism in ipRGCs (La Morgia et al., 2011; Feigl and Zele, 2014). However, ipRGCs and their function are not spared in all neurodegenerative diseases: ipRGC function is altered in patients with age-related macular degeneration (Cui et al., 2015; Maynard et al., 2015), in patients and animal models with glaucoma (Cooper and Mure, 2008; Drouyer et al., 2008; Wang et al., 2008; Perez-Rico et al., 2010; Feigl et al., 2011; Kankipati et al., 2011; Nissen et al., 2014), and in Alzheimer's disease (La Morgia et al., 2016). Resistance of melanopsin ${ }^{+}$ipRGCs in our Ikbkap CKO retinas to degeneration (Fig. $7 D, E$ ) and similarities in overall retinal phenotype with other mitochondrial retinopathies (e.g., LOHN and DOA) potentially point to a shared disruption in mitochondrial function. It is worth mentioning, however, that although the GFP Cre reporter was expressed in ipRGCs, it is theoretically possible that the resistance to death of ipRGCs in our CKO is due to residual IKAP protein expression.

Although we have shown that loss of Ikbkap in CKO mice causes slow, progressive RGC degeneration (Fig. 5) followed by photoreceptor degeneration (Fig. 8) and retinal disorganization (Fig. 3), these phenotypes were observed in To1-Cre Ikbkap CKO mice that have a systematic neuronal deletion of Ikbkap causing a severe progressive neuropathy that could indirectly generate these retinal deficits. In addition, with this model we are unable to analyze the consequence of lkbkap loss in retinal cell types other than RGCs, since expression of $T \alpha 1-C r e$ is primarily restricted to RGCs in the retina (Fig. 2). Therefore, we are currently generating retina-specific Ikbkap CKO mice to analyze direct consequences of $I k b$ kap loss in all retinal neuron subtypes and be able to distinguish autonomous versus nonautonomous require- 
ments for lkbkap in various retinal populations. Nonetheless, this is the first study that not only identified the endogenous expression pattern of Ikbkap in the retina, but also characterized the retinal phenotype and pathology that are the consequences of the absence of Ikbkap in RGCs. The phenotypes observed in our CKO retinas were remarkably similar to clinical presentation of FD patients' retinas (Mendoza-Santiesteban et al., 2012, 2014).

Although one of the most debilitating hallmarks of FD as patients age is progressive blindness, the pathophysiological mechanisms underlying the loss of vision have not been the focus of any study. With our T $\alpha 1$-Cre Ikbkap CKO model of FD blindness, not only are we able to investigate the course and causes of disease progression, but we also have established an in vivo model system for testing potential therapeutics for mitigating the progressive optic neuropathy in FD patients.

\section{References}

Abashidze A, Gold V, Anavi Y, Greenspan H, Weil M (2014) Involvement of IKAP in peripheral target innervation and in specific JNK and NGF signaling in developing PNS neurons. PloS One 9:e113428. CrossRef Medline

Anderson SL, Coli R, Daly IW, Kichula EA, Rork MJ, Volpi SA, Ekstein $J$, Rubin BY (2001) Familial dysautonomia is caused by mutations of the IKAP gene. Am J Hum Genet 68:753-758. CrossRef Medline

Applebury ML, Antoch MP, Baxter LC, Chun LL, Falk JD, Farhangfar F, Kage K, Krzystolik MG, Lyass LA, Robbins JT (2000) The murine cone photoreceptor: a single cone type expresses both $S$ and $M$ opsins with retinal spatial patterning. Neuron 27:513-523. Medline

Axelrod FB (2002) Hereditary sensory and autonomic neuropathies. Familial dysautonomia and other HSANs. Clin Autonom Res 12: Suppl 1:12-14. CrossRef

Bauer F, Hermand D (2012) A coordinated codon-dependent regulation of translation by Elongator. Cell Cycle 11:4524-4529. CrossRef Medline

Berson DM, Dunn FA, Takao M (2002) Phototransduction by retinal ganglion cells that set the circadian clock. Science 295:10701073. CrossRef Medline

Bochner R, Ziv Y, Zeevi D, Donyo M, Abraham L, Ashery-Padan R, Ast $G$ (2013) Phosphatidylserine increases IKBKAP levels in a humanized knock-in IKBKAP mouse model. Hum Mol Genet 22: 2785-2794. CrossRef

Carelli V, La Morgia C, Valentino ML, Barboni P, Ross-Cisneros FN, Sadun AA (2009) Retinal ganglion cell neurodegeneration in mitochondrial inherited disorders. Biochim Biophys Acta 1787:518528. CrossRef Medline

Chen SK, Badea TC, Hattar S (2011) Photoentrainment and pupillary light reflex are mediated by distinct populations of ipRGCs. Nature 476:92-95. CrossRef Medline

Chen YT, Hims MM, Shetty RS, Mull J, Liu L, Leyne M, Slaugenhaupt SA (2009) Loss of mouse Ikbkap, a subunit of elongator, leads to transcriptional deficits and embryonic lethality that can be rescued by human IKBKAP. Mol Cell Biol 29:736-744. CrossRef Medline

Chevrollier A, Guillet V, Loiseau D, Gueguen N, de Crescenzo MA, Verny C, Ferre M, Dollfus H, Odent S, Milea D, Goizet C, AmatiBonneau P, Procaccio V, Bonneau D, Reynier P (2008) Hereditary optic neuropathies share a common mitochondrial coupling defect. Ann Neurol 63:794-798. CrossRef

Chollangi S, Wang J, Martin A, Quinn J, Ash JD (2009) Preconditioning-induced protection from oxidative injury is mediated by leukemia inhibitory factor receptor (LIFR) and its ligands in the retina. Neurobiol Dis 34:535-544. CrossRef Medline

Coksaygan T, Magnus T, Cai J, Mughal M, Lepore A, Xue H, Fischer I, Rao MS (2006) Neurogenesis in Talpha-1 tubulin transgenic mice during development and after injury. Exp Neurol 197:475-485. CrossRef Medline
Cooper HM, Mure LS (2008) Expected and unexpected properties of melanopsin signaling. J Biol Rhythms 23:392-393. CrossRef Medline

Coppola V, Barrick CA, Southon EA, Celeste A, Wang K, Chen B, Haddad el B, Yin J, Nussenzweig A, Subramaniam A, Tessarollo L (2004) Ablation of TrkA function in the immune system causes $B$ cell abnormalities. Development 131:5185-5195. CrossRef Medline

Cuajungco MP, Leyne M, Mull J, Gill SP, Lu W, Zagzag D, Axelrod FB, Maayan C, Gusella JF, Slaugenhaupt SA (2003) Tissuespecific reduction in splicing efficiency of IKBKAP due to the major mutation associated with familial dysautonomia. Am J Hum Genet 72:749-758. CrossRef Medline

Cui Q, Ren C, Sollars PJ, Pickard GE, So KF (2015) The injury resistant ability of melanopsin-expressing intrinsically photosensitive retinal ganglion cells. Neuroscience 284:845-853. CrossRef Medline

DeParis S, Caprara C, Grimm C (2012) Intrinsically photosensitive retinal ganglion cells are resistant to $N$-methyl-d-aspartic acid excitotoxicity. Mol Vis 18:2814-2827. Medline

Dietrich P, Dragatsis I (2016) Familial dysautonomia: mechanisms and models. Genet Mol Biol

Dietrich P, Yue J, Shuyu E, Dragatsis I (2011) Deletion of exon 20 of the familial dysautonomia gene Ikbkap in mice causes developmental delay, cardiovascular defects, and early embryonic lethality. PloS One 6:e27015. CrossRef

Dietrich P, Alli S, Shanmugasundaram R, Dragatsis I (2012) IKAP expression levels modulate disease severity in a mouse model of familial dysautonomia. Hum Mol Genet 21:5078-5090. CrossRef

Drouyer E, Dkhissi-Benyahya O, Chiquet C, WoldeMussie E, Ruiz G, Wheeler LA, Denis P, Cooper HM (2008) Glaucoma alters the circadian timing system. PloS One 3:e3931CrossRef Medline

Esberg A, Huang B, Johansson MJ, Bystrom AS (2006) Elevated levels of two tRNA species bypass the requirement for elongator complex in transcription and exocytosis. Mol Cell 24:139-148. CrossRef Medline

Estevez ME, Fogerson PM, Ilardi MC, Borghuis BG, Chan E, Weng S, Auferkorte ON, Demb JB, Berson DM (2012) Form and function of the M4 cell, an intrinsically photosensitive retinal ganglion cell type contributing to geniculocortical vision. J Neurosci 32:1360813620. CrossRef

Feigl B, Zele AJ (2014) Melanopsin-expressing intrinsically photosensitive retinal ganglion cells in retinal disease. Optom Vis Sci 91:894-903. CrossRef Medline

Feigl B, Mattes D, Thomas R, Zele AJ (2011) Intrinsically photosensitive (melanopsin) retinal ganglion cell function in glaucoma. Invest Ophthalmol Vis Sc 52:4362-4367. CrossRef Medline

Galindo-Romero C, Aviles-Trigueros M, Jimenez-Lopez M, ValienteSoriano FJ, Salinas-Navarro M, Nadal-Nicolas F, Villegas-Perez MP, Vidal-Sanz M, Agudo-Barriuso M (2011) Axotomy-induced retinal ganglion cell death in adult mice: quantitative and topographic time course analyses. Exp Eye Res 92:377-387. CrossRef Medline

George L, Chaverra M, Wolfe L, Thorne J, Close-Davis M, Eibs A, Riojas V, Grindeland A, Orr M, Carlson GA, Lefcort F (2013) Familial dysautonomia model reveals Ikbkap deletion causes apoptosis of Pax3+ progenitors and peripheral neurons. Proc Natl Acad Sci USA 110:18698-18703. CrossRef Medline

Gloster A, Wu W, Speelman A, Weiss S, Causing C, Pozniak C, Reynolds B, Chang E, Toma JG, Miller FD (1994) The T alpha 1 alpha-tubulin promoter specifies gene expression as a function of neuronal growth and regeneration in transgenic mice. J Neurosci 14:7319-7330.

Gold-von Simson G, Axelrod FB (2006) Familial dysautonomia: update and recent advances. Curr Probl Pediatr Adolesc Health Care 36:218-237. CrossRef Medline

Goldberg MF, Payne JW, Brunt PW (1968) Ophthalmologic studies of familial dysautonomia. The Riley-Day syndrome. Arch Ophthalmol 80:732-743. Medline 
Hims MM, Shetty RS, Pickel J, Mull J, Leyne M, Liu L, Gusella JF, Slaugenhaupt SA (2007) A humanized IKBKAP transgenic mouse models a tissue-specific human splicing defect. Genomics 90: 389-396. CrossRef Medline

Huang B, Johansson MJ, Bystrom AS (2005) An early step in wobble uridine tRNA modification requires the Elongator complex. rna 11:424-436. CrossRef Medline

Hunnicutt BJ, Chaverra M, George L, Lefcort F (2012) IKAP/Elp1 is required in vivo for neurogenesis and neuronal survival, but not for neural crest migration. PloS One 7:e32050. CrossRef Medline

Ito D, Tanaka K, Suzuki S, Dembo T, Fukuuchi Y (2001) Enhanced expression of Iba1, ionized calcium-binding adapter molecule 1, after transient focal cerebral ischemia in rat brain. Stroke 32:12081215. Medline

Jackson MZ, Gruner KA, Qin C, Tourtellotte WG (2014) A neuron autonomous role for the familial dysautonomia gene ELP1 in sympathetic and sensory target tissue innervation. Development 141: 2452-2461. CrossRef Medline

Kankipati L, Girkin CA, Gamlin PD (2011) The post-illumination pupil response is reduced in glaucoma patients. Invest Ophthalmol Vis Sci 52:2287-2292. CrossRef Medline

Kirches E (2011) LHON: mitochondrial mutations and more. Curr Genom 12:44-54. CrossRef Medline

La Morgia C, Ross-Cisneros FN, Hannibal J, Montagna P, Sadun AA, Carelli V (2011) Melanopsin-expressing retinal ganglion cells: implications for human diseases. Vis Res 51:296-302. CrossRef Medline

La Morgia C, Ross-Cisneros FN, Sadun AA, Hannibal J, Munarini A, Mantovani V, Barboni P, Cantalupo G, Tozer KR, Sancisi E, Salomao SR, Moraes MN, Moraes-Filho MN, Heegaard S, Milea D, Kjer P, Montagna P, Carelli V (2010) Melanopsin retinal ganglion cells are resistant to neurodegeneration in mitochondrial optic neuropathies. Brain 133:2426-2438. CrossRef

La Morgia C, Ross-Cisneros FN, Koronyo Y, Hannibal J, Gallassi R, Cantalupo G, Sambati L, Pan BX, Tozer KR, Barboni P, Provini F, Avanzini $P$, Carbonelli M, Pelosi A, Chui H, Liguori R, Baruzzi A, Koronyo-Hamaoui M, Sadun AA, Carelli V (2016) Melanopsin retinal ganglion cell loss in Alzheimer disease. Ann Neurol 79:90-109. CrossRef Medline

LaVail MM, Unoki K, Yasumura D, Matthes MT, Yancopoulos GD, Steinberg RH (1992) Multiple growth factors, cytokines, and neurotrophins rescue photoreceptors from the damaging effects of constant light. Proc Natl Acad Sci USA 89:11249-11253. Medline

Li SY, Yau SY, Chen BY, Tay DK, Lee VW, Pu ML, Chan HH, So KF (2008) Enhanced survival of melanopsin-expressing retinal ganglion cells after injury is associated with the PI3 K/Akt pathway. Cell Mol Neurobiol 28:1095-1107. CrossRef Medline

Liebman SD (1968) Riley-Day syndrome: long-term ophthalmologic observations. Trans Am Ophthalmol Soc 66:95-116. Medline

Maynard ML, Zele AJ, Feigl B (2015) Melanopsin-mediated postillumination pupil response in early age-related macular degeneration. Invest Ophthalmol Vis Sci 56:6906-6913. CrossRef Medline

Mendoza-Santiesteban CE, Hedges lii TR, Norcliffe-Kaufmann L, Axelrod F, Kaufmann H (2014) Selective retinal ganglion cell loss in familial dysautonomia. J Neurol 261:702-709. CrossRef Medline

Mendoza-Santiesteban CE, Hedges TR, 3rd, Norcliffe-Kaufmann L, Warren F, Reddy S, Axelrod FB, Kaufmann H (2012) Clinical neuroophthalmic findings in familial dysautonomia. $\mathrm{J}$ Neuro-Ophthalmol 32:23-26. CrossRef

Mezey E, Parmalee A, Szalayova I, Gill SP, Cuajungco MP, Leyne M, Slaugenhaupt SA, Brownstein MJ (2003) Of splice and men: what does the distribution of IKAP mRNA in the rat tell us about the pathogenesis of familial dysautonomia? Brain Res 983:209-214. Medline

Morini E, Dietrich P, Salani M, Downs HM, Wojtkiewicz GR, Alli S, Brenner A, Nilbratt M, LeClair JW, Oaklander AL, Slaugenhaupt SA, Dragatsis I (2016) Sensory and autonomic deficits in a new humanized mouse model of familial dysautonomia. Hum Mol Genet 25:1116-1128. CrossRef
Moura AL, Nagy BV, La Morgia C, Barboni P, Oliveira AG, Salomao SR, Berezoversusky A, de Moraes-Filho MN, Chicani CF, Belfort R, Jr., Carelli V, Sadun AA, Hood DC, Ventura DF (2013) The pupil light reflex in Leber's hereditary optic neuropathy: evidence for preservation of melanopsin-expressing retinal ganglion cells. Invest Ophthalmol Vis Sci 54:4471-4477. CrossRef

Muzumdar MD, Tasic B, Miyamichi K, Li L, Luo L (2007) A global double-fluorescent Cre reporter mouse. Genesis 45:593-605. CrossRef Medline

Nadal-Nicolas FM, Jimenez-Lopez M, Sobrado-Calvo P, NietoLopez L, Canovas-Martinez I, Salinas-Navarro M, Vidal-Sanz M, Agudo M (2009) Brn3a as a marker of retinal ganglion cells: qualitative and quantitative time course studies in naive and optic nerve-injured retinas. Invest Ophthalmol Vis Sci 50:3860-3868. CrossRef Medline

Newman NJ, Biousse V (2004) Hereditary optic neuropathies. Eye 18:1144-1160. CrossRef Medline

Nissen C, Sander B, Milea D, Kolko M, Herbst K, Hamard P, LundAndersen $\mathrm{H}$ (2014) Monochromatic pupillometry in unilateral glaucoma discloses no adaptive changes subserved by the ipRGCs. Front Neurol 5:15. CrossRef Medline

Norcliffe-Kaufmann L, Slaugenhaupt SA, Kaufmann H (2016) Familial dysautonomia: history, genotype, phenotype and translational research. Prog Neurobiol

Otsu N (1979) A Threshold Selection Method from Gray-Level Histograms. IEEE Trans Syst Man Cybernet 9:62-66. CrossRef

Palma JA, Norcliffe-Kaufmann L, Fuente-Mora C, Percival L, Mendoza-Santiesteban C, Kaufmann H (2014) Current treatments in familial dysautonomia. Expert Opin Pharmacother 15:26532671. CrossRef Medline

Perez de Sevilla Muller L, Sargoy A, Rodriguez AR, Brecha NC (2014) Melanopsin ganglion cells are the most resistant retinal ganglion cell type to axonal injury in the rat retina. PloS One 9:e93274. CrossRef Medline

Perez-Rico C, de la Villa P, Arribas-Gomez I, Blanco R (2010) Evaluation of functional integrity of the retinohypothalamic tract in advanced glaucoma using multifocal electroretinography and light-induced melatonin suppression. Exp Eye Res 91:578-583. CrossRef Medline

Riley CM, Day RL, et al. (1949) Central autonomic dysfunction with defective lacrimation; report of five cases. Pediatrics 3:468-478. Medline

Robinson GA, Madison RD (2004) Axotomized mouse retinal ganglion cells containing melanopsin show enhanced survival, but not enhanced axon regrowth into a peripheral nerve graft. Vis Res 44:2667-2674. CrossRef

Rodriguez AR, de Sevilla Muller LP, Brecha NC (2014) The RNA binding protein RBPMS is a selective marker of ganglion cells in the mammalian retina. J Comp Neur 522:1411-1443. CrossRef Medline

Slaugenhaupt SA, Blumenfeld A, Gill SP, Leyne M, Mull J, Cuajungco MP, Liebert CB, Chadwick B, Idelson M, Reznik L, Robbins C, Makalowska I, Brownstein M, Krappmann D, Scheidereit C, Maayan C, Axelrod FB, Gusella JF (2001) Tissue-specific expression of a splicing mutation in the IKBKAP gene causes familial dysautonomia. Am J Hum Genet 68:598-605. Medline

Tigano M, Ruotolo R, Dallabona C, Fontanesi F, Barrientos A, Donnini C, Ottonello S (2015) Elongator-dependent modification of cytoplasmic tRNALysUUU is required for mitochondrial function under stress conditions. Nucl Acids Res 43:8368-8380. CrossRef Medline

Ueki Y, Wang J, Chollangi S, Ash JD (2008) STAT3 activation in photoreceptors by leukemia inhibitory factor is associated with protection from light damage. J Neurochem 105:784-796. CrossRef Medline

Wang HZ, Lu QJ, Wang NL, Liu H, Zhang L, Zhan GL (2008) Loss of melanopsin-containing retinal ganglion cells in a rat glaucoma model. Chin Med J (Engl) 121:1015-1019. Medline [Mismatch]

Xiang M, Zhou L, Macke JP, Yoshioka T, Hendry SH, Eddy RL, Shows TB, Nathans J (1995) The Brn-3 family of POU-domain 
factors: primary structure, binding specificity, and expression in subsets of retinal ganglion cells and somatosensory neurons. $J$ Neurosci 15:4762-4785.

Xu H, Lin Z, Li F, Diao W, Dong C, Zhou H, Xie X, Wang Z, Shen Y, Long $J$ (2015) Dimerization of elongator protein 1 is essential for Elongator complex assembly. Proc Natl Acad Sci USA 112:1069710702. CrossRef Medline

Yu H, Ozdemir SS, Koilkonda RD, Chou TH, Porciatti V, Chiodo V, Boye SL, Hauswirth WW, Lewin AS, Guy J (2012) Mutant NADH dehydrogenase subunit 4 gene delivery to mitochondria by target- ing sequence-modified adeno-associated virus induces visual loss and optic atrophy in mice. Mol Vis 18:1668-1683. Medline

Yu-Wai-Man P, Votruba M, Moore AT, Chinnery PF (2014) Treatment strategies for inherited optic neuropathies: past, present and future. Eye 28:521-537. CrossRef Medline

Zanna C, Ghelli A, Porcelli AM, Karbowski M, Youle RJ, Schimpf S, Wissinger B, Pinti M, Cossarizza A, Vidoni S, Valentino ML, Rugolo M, Carelli V (2008) OPA1 mutations associated with dominant optic atrophy impair oxidative phosphorylation and mitochondrial fusion. Brain 131:352-367. CrossRef 